\title{
After the Break-Up: The Relational and Reputational Consequences of Withdrawals from Venture Capital Syndicates
}

\author{
PAVEL I. ZHELYAZKOV* \\ The Department of Management \\ The Lee Shau Kee Business Building \\ Clear Water Bay, Kowloon, Hong Kong \\ Tel: +852-2358-7760 \\ E-mail:pzhelyazkov@ust.hk \\ RANJAY GULATI \\ Harvard Business School \\ Organizational Behavior Unit \\ Morgan Hall \\ Boston, MA 02163, USA \\ Tel: +1-617-495-8554 \\ E-mail: rgulati@hbs.edu
}

The Hong Kong University of Science and Technology

Forthcoming in the Academy of Management Journal

\footnotetext{
${ }^{*}$ Corresponding author. We are grateful to Gerald George and three anonymous reviewers for their constructive suggestions through the review process. The paper has benefited greatly from feedback from seminar participants at Harvard Business School, London Business School, and the Academy of Management. We particularly thank Alicia DeSantola, Javier Gimeno, Paul Gompers, Michael Jensen, Chris Marquis, Peter Marsden, Ray Reagans, Andrew Shipilov, Sameer Srivastava, Maxim Sytch, Andras Tilcsik, Magnus Torfason, and Chris Winship for their thoughtful comments and suggestions. All errors are our own. An earlier, abridged version of this paper was published in the Academy of Management Best Paper Proceedings (2013).
} 


\title{
After the Break-Up: The Relational and Reputational Consequences of Withdrawals from Venture Capital Syndicates
}

\begin{abstract}
Organizational theorists are increasingly interested in the antecedents of terminating interorganizational relationships, but have paid little attention to the disruptive consequences of such terminations on future tie formation. To redress this imbalance, the present study focuses on how venture capital (VC) firms' withdrawals from VC syndicates are associated with their subsequent syndication over the 1985 through 2008 period. We argue that withdrawals disrupt the relationships of the withdrawing VC firms with the coinvestors and reduce the likelihood of them entering into subsequent exchange (relational consequences). Furthermore, public information on the withdrawals can undermine the withdrawing VC firm's reputation for reliability, making it a less desirable exchange partner overall (global reputational consequences). Finally, we find that abandoned coinvestors can spread negative, private information about the withdrawing firm, reducing its chances of syndication with their other network contacts (local reputational consequences). We also show that the global and local reputational consequences attenuate each other, due to redundancy in the content of information each provides. We discuss the implications of our theory for the research on network dynamics and reputation.
\end{abstract}




\section{INTRODUCTION}

Organizational theorists have long been interested in the drivers of collaboration partner selection in various settings, such as strategic alliances (Ahuja, 2000; Gulati, 1995b), investment bank syndicates (Podolny, 1994; Shipilov \& Li, 2012), and venture capital (VC) syndicates (Sorenson \& Stuart, 2008; Trapido, 2007). Much of this research has been concerned with how the history of prior tie formation can facilitate the development of future collaborative ties. The literature's overwhelming consensus is that prior collaborations facilitate the development of trust and social attachments that increase the likelihood that actors will select their partners for future collaborations (Dyer \& Singh, 1998; Gulati, 1995b; Li \& Rowley, 2002). Indirect ties via shared partners can also serve as conduits for introductions, referrals, and endorsements, increasing the likelihood that indirectly connected actors will form direct connections with each other (Gulati \& Gargiulo, 1999; Shane \& Cable, 2002).

The view that the history of prior relationships enables the formation of new relationships implicitly relies on the assumption that all collaborations proceed as planned and thus strengthen the bond connecting the collaborating parties. ${ }^{1}$ Increasing evidence, however, shows that not all collaborations end well. For example, by some accounts more than fifty percent of strategic alliances dissolve before achieving their objectives (Kale \& Singh, 2009), and other field studies

\footnotetext{
${ }^{1}$ A rare exception to this view at the interorganizational level is the work of Li and Rowley (2002), who found that poor performance of an investment banking syndicate reduces the likelihood that the participating investment banks would collaborate in the future. At the interpersonal level, Labianca and colleagues explored the antecedents and consequences of conflict and negative reputation among coworkers (Labianca \& Brass, 2006; Labianca, Brass, \& Gray, 1998).
} 
have suggested that some of those dissolutions are acrimonious affairs, resulting in mutual frustration, strained relationships, and deep distrust between the former collaborators (Arino \& de la Torre, 1998; Doz, 1996; Faems, Janssens, Madhok, \& Van Looy, 2008; Gulati, Sytch, \& Mehrotra, 2008). Similarly, in a different context, the withdrawal of VC firms from syndicates with other VC firms is highly disruptive for the portfolio companies, and field studies suggest that it can poison relationships with the abandoned coinvestors (e.g. Guler, 2007). A heightened appreciation of the importance of tie dissolutions has led to a growing effort to understand their antecedents (Greve, Baum, Mitsuhashi, \& Rowley, 2010; Greve, Mitsuhashi, \& Baum, 2013; Polidoro, Ahuja, \& Mitchell, 2011). To date, however, few studies have examined the consequences of tie dissolutions on future tie formation.

Understanding the consequences of dissolutions is important because the relationship disruptions they cause can undermine the taken-for-granted relationships between past and future tie formation. At the dyadic level, scholars typically assume that past collaborations are associated with growing familiarity and trust that facilitate future exchange (Gulati, 1995a). Allowing for tie termination, however, can help us uncover that not all ties are created equal and that some may indeed subsequently unravel. This, in turn, can undermine trust, cause the relationship to deteriorate, and reduce the likelihood of repeat collaborations. At the triadic level, actors often select alters with whom they shared a past collaboration partner, in part because positive referrals flow through the mutually trusted third party (Gulati, 1995b; Gulati \& Gargiulo, 1999; Shane \& Cable, 2002). Referrals flowing through the indirect tie may turn negative, however, and thus reduce the likelihood of collaboration between the two parties if either of them terminates the relationship with the shared partner. 
Tie dissolutions also have important implications for our understanding of organizational reputation. Existing research has widely assumed that an organization’s centrality in the interorganizational network can act as a positive signal of its attractiveness as a collaboration partner (Ahuja, Polidoro, \& Mitchell, 2009; Gulati, 2007; Gulati \& Gargiulo, 1999). In contrast, we propose that the withdrawal of an organization from an ongoing collaboration can send the opposite signal: that it is an unreliable and thus undesirable partner. Such inferences can form the basis of a negative reputation that could limit an organization’s ability to form future relationships. Conceptualizing tie dissolutions as reputation-impairing events allows us to distinguish between the effects of different sources of negative information. For example, we can learn how a focal actor's willingness to form a tie with a particular alter ${ }^{2}$ is affected by 1 ) publicly available negative information, based on the alter's publicly observable history of tie dissolution; and 2) privately-sourced negative information, based on the focal actor's social connections to actors whom the alter has previously abandoned and who are therefore especially likely to pass on negative information about the alter.

We set our study in the context of VC firm withdrawals from venture capital syndicates, defined as the joint investment of two or more VC firms in a portfolio company that involves significant financial contributions and managerial oversight and guidance. Such syndicates have long been of interest to both finance (Hochberg, Ljungqvist, \& Lu, 2007, 2010; Lerner, 1994) and organizational scholars (Podolny, 2001; Sorenson \& Stuart, 2001, 2008). Typically, venture capital investments are disbursed in rounds conditional on the portfolio company’s progress

\footnotetext{
${ }^{2}$ For consistency, in the remainder of the paper, we take the perspective of the actor who selects a collaboration partner ("the focal actor") and consider the "alter" the actor that is evaluated as a potential partner.
} 
(Gompers, 1995). Venture capital firms can withdraw at any stage of the collaboration; however, prior research has indicated that significant pressures exist from the coinvestors to remain in the syndicate even if its chances of success deteriorate (Guler, 2007). The present work is the only research to date that examines an important consequence of withdrawal decisions: the ability of VC firms to enter into future syndication relationships.

We explore the consequences of such withdrawals on three levels. First, at the relational level, we predict that the withdrawal can lead to disrupting the relationship with the coinvestors and reducing their willingness to syndicate with the withdrawing firm in the future. Second, at the global reputational level, we hypothesize that the publicly available track record of the firm's withdrawals can signal its lack of reliability and cause prospective syndication partners to be more wary of entering into a relationship with it. Third, at the local reputational level, we propose that abandoned coinvestors may spread negative private information about the withdrawing firm, reducing the likelihood that their immediate network contacts will enter into a

syndicate with it. We also examine how the global and local reputational consequences interact with one another by testing the idea that the negative private information available from abandoned coinvestors can draw attention to and validate any existing publicly available negative information.

\section{THEORY AND HYPOTHESES}

\section{The Context: The Venture Capital Industry}

The VC industry has played an important role in supporting entrepreneurship and innovations in a range of industries, including biotechnology, information technology, and 
energy (Gompers \& Lerner, 2001). It functions as a gatekeeper, selecting promising new ventures (called portfolio companies) for continued investment and support. It also serves as an intermediary, linking capital providers-large institutions such as endowments, foundations, and pension funds-with young, nonpublic companies that need funds. Such young companies potentially can return the investment many times over in the case of an initial public offering (IPO) or an acquisition by an established industry actor. Finally, VCs can provide significant nonfinancial support for their portfolio companies, including strategic guidance and direction (Gorman \& Sahlman, 1989), connections with prospective customers, suppliers, alliance partners or acquirors (Lindsey, 2008), as well as signaling the value of the portfolio company in the larger marketplace (Lee, Pollock, \& Jin, 2011; Stuart, Hoang, \& Hybels, 1999).

VC firms commonly form syndicates and invest in the same portfolio company for several reasons. Syndication allows them to share the financial risk and diversify their portfolio more effectively by spreading their capital over a larger number of companies (Wilson, 1968). Coinvestors are also expected to contribute nonfinancial resources, such as participating in the due diligence process, sitting on the company’s board, providing management advice and coaching, and promoting the company within their own networks (Gorman \& Sahlman, 1989). Pooling the resources and capabilities of a variety of investors increases the probability of success for the syndicate (Hochberg, Lindsay, \& Westerfield, forthcoming), but requires the trust and commitment that all participants will meet their obligations (Sorenson \& Stuart, 2008). As a result, VCs are highly selective in choosing their syndication partners, and they present a compelling setting to study the formation of interorganizational relationships.

Traditionally, organizational and finance scholars have drawn on two major drivers of syndication partner selection. First, scholars have focused on the resources that can increase the 
attractiveness of a VC as a syndication partner, such as deep reserves of capital (Hochberg et al., forthcoming), extensive experience in the industry of the portfolio company (Lerner, 1994), status in the interorganizational network (Piskorski \& Anand, 2011), or the human capital of the individual venture capitalists (Gompers, Mukharlyamov, \& Xuan, forthcoming). The guiding logic of this stream of research is that better endowed VCs can be expected to make higherquality contributions and would thus be more likely to be invited to syndicates. The second stream of research focuses on how mechanisms such as trust or familiarity explain the preference for similar or structurally proximate VCs. For example, VCs have a marked preference for syndicating with past coinvestors or VCs that are close in the syndication network (Sorenson \& Stuart, 2001).Venture capital firms also disproportionately select coinvestors with similar geographic and industry specialization (Trapido, 2007). At the interpersonal level, VCs tend to invite disproportionately more coethnics and former classmates to join their syndication deals (Gompers et al., forthcoming).

Although scholars have conducted extensive work on what drives syndication, there has been little attention to withdrawals from syndication relationships. Venture capital firms disburse investments in rounds, with each conditional on the venture achieving specified milestones. Staging an investment limits investors' commitments at the outset, when uncertainty is highest, and keeps a tight leash on an entrepreneur who depends on subsequent cash infusions (Gompers, 1995). Legally, a VC firm is free to terminate its participation at any round, even though significant incentives are included in syndication agreements to prevent defections. ${ }^{3}$ Importantly,

\footnotetext{
${ }^{3}$ Such penalties can take the form of "pay-to-play” provisions, which require a VC to maintain its financial contributions in order to retain its seat on the portfolio company's board and enjoy price guarantees on the shares that it has acquired in the previous rounds. Alternatively, dilution provisions specify that a defector's ownership share in the portfolio company will be diluted significantly in the subsequent round.
} 
syndication contracts in the US almost universally include the right of a VC firm to participate in each future round at the rate of its prior stake in the company. This means that a firm can never be excluded from the syndicate against its own wishes. ${ }^{4}$

Limited empirical research has examined the antecedents and consequences of VC withdrawals from syndicates. Townsend (forthcoming) explored the effect of VCs' liquidity constraints on their ability to continue participating in syndicates and the negative effect of such withdrawals on the performance outcomes of otherwise high-quality companies. In an important early exploration of this question, Guler (2007) documented how pressures from coinvestors and concerns about disrupting valuable relationships may keep VCs from abandoning underperforming deals. Guler’s work, however, leaves as an open question whether such pressures indeed translate into real penalties following the withdrawal. The present research aims to answer this question directly.

\section{The Relational Consequences of Withdrawals}

In prior studies, organizational scholars have focused on how the history of exchange relationships deepens the ties between collaborators, which leads to the development of trust and social attachments that increase the probability of tie renewal (Gulati \& Sytch, 2008; Seabright, Levinthal, \& Fichman, 1992). Researchers have become increasingly aware, however, that this process is contingent on a positive experience with the exchange partner. Dissatisfaction with the

\footnotetext{
${ }^{4}$ Informal discussions with several venture capitalists and industry experts suggest that withdrawals by participating VCs in a venture from subsequent rounds can occur for three major reasons. First, a VC firm may lose confidence in the prospects of the portfolio company or decide that its limited capital is useful for other purposes. Second, a VC firm may be too resource constrained to participate in the round. Third, some smaller firms tend to specialize exclusively in earlier stages and thus may have agreed upfront to withdraw in the later rounds. In the present study, we are interested in withdrawals of the first type, because they involve the VC's conscious decision to part ways with its coinvestors. In the present study's data and methods section, we discuss approaches to ensure that the other two possible drivers of withdrawal do not impact our results.
} 
collaboration can serve as a negative relationship shock (Azoulay, Repenning, \& Zuckerman, 2010; Chung \& Beamish, 2010) that makes repeated collaborations less likely (Li \& Rowley, 2002; Schwab \& Miner, 2008). Along similar lines, we propose that a firm withdrawing from a syndicate can also be considered a negative shock that will reduce the likelihood of syndication with the coinvestors. We posit this for two reasons.

Direct experience of withdrawals can lead the coinvestors to question the reliability of the withdrawing VC firm: an attribute that venture capitalists care deeply about. Unexpected withdrawals can be highly disruptive to the collaboration because they create a funding shortfall, deprive the venture of managerial expertise, and send a negative signal that can potentially hobble the syndicate's ability to recruit new outside investors (Townsend, forthcoming). Withdrawals can thus jeopardize the capital and time that the remaining collaborators have invested in the venture. As a result, the track record of reliably providing support to prior investments can be a criterion by which VCs evaluate their prospective partners. According to an interviewed VC principal, VCs "want a good partner, someone who would stick with the company through thick and thin.” Abandoned coinvestors can take the focal VC's withdrawal as a direct signal of its character and are more likely to expect a withdrawal from that VC in the future. Naturally, this would make the VC a less attractive syndication partner for the abandoned coinvestors.

Beyond the pure signaling value of withdrawals, a withdrawal can undermine the quality of the relationship between the withdrawing VC and its syndication partners. Syndication between VC firms involves close collaborations between the principals that each VC nominates to represent it at the board of directors (e.g., Gorman \& Sahlman, 1989). The trust and the interpersonal attachments existing between the principals of VC firms thus play a major role in 
syndication decisions (Gompers et al., forthcoming; Rider, 2012). Exchange theorists have proposed that the process of successful exchange generates positive emotions that the individual participants attribute to the relationship and their collaboration partners (Lawler, 2001; Lawler \& Yoon, 1998); such attributions, in turn, lead to deepening attachments and a willingness to continue the exchange even if more attractive alternatives were available (Lawler, Thye, \& Yoon, 2000). In the present study, we propose that terminating exchange relationships could have the opposite effect; that is, the withdrawal is likely to generate negative emotions that become attached to the relationship and might increase the aversion of the abandoned principals to engaging again with the withdrawing partner. An interpersonal relationship breakdown can easily translate into an interorganizational relationship breakdown. Given that VC firms are tightly knit and cohesive entities, and typically every major investment decision can be vetoed by any single partner, the interpersonal relationships disrupted by withdrawal can lead to a diminished likelihood of future syndication between the abandoned VC firms and the withdrawing firm.

In summary, experiencing a withdrawal can have signaling implications (i.e., reevaluation of the reliability of the withdrawing firm) as well as interpersonal relationship implications (i.e., worsened relationship between the principals involved on both sides). Taken together, these two mechanisms suggest that the withdrawal might have relational costs, ${ }^{5}$

\footnotetext{
${ }^{5}$ Our choice of terminology derives from Gulati's (1995b) use of the term: just as "relational embeddedness" refers to the existence of a prior relationship and how it can facilitate the formation of repeat alliance ties, the relational costs of withdrawal refer to how the direct experience of a withdrawal can diminish the likelihood of future syndication.
} 
including the decreased likelihood of the withdrawing VC to secure future syndications with the abandoned partners. This leads to the following hypothesis:

Hypothesis 1: A focal VC firm is less likely to syndicate with alters that have previously withdrawn from a greater proportion of their syndicates with the focal VC.

\section{The Global Reputational Consequences of Withdrawal}

Although some withdrawal consequences—such as the relationship deterioration—are clearly dyadic, a withdrawal from a VC syndicate may have broader repercussions; namely, implications for the exchange partner's reputation for reliability. Here, we use the classic definition of reputation as “a set of attributes ascribed to a firm, inferred from the firm's past actions” (Weigelt \& Camerer, 1988: 443). The starting point is the idea that the true attributes of interest are unobservable but can be inferred from the firm's past actions or achievements. These inferences, in turn, inform actors’ decisions regarding whether to conduct an exchange with an organization (e.g., Dollinger, Golden, \& Saxton, 1997; Sullivan, Haunschild, \& Page, 2007).

Our interviews suggested that within the VC context, the reliability of expected support is a crucial consideration when selecting syndication partners. In assessing the likelihood of continued support, VCs tend to look both at the hard data of the prospective partner's ability to participate in future rounds, as well as the soft data of the partner's willingness to consistently support the syndicate, including the history of and reasons for withdrawals. Withdrawals can raise many concerning questions about a VC's reliability, for example, how difficult is it to work with and how committed it is to supporting its portfolio companies. The proliferation of industry databases covering VC investment, syndication, and withdrawal decisions—such as VentureXpert, Preqin, and Pitchbooks_-means that most withdrawal decisions will be globally 
observable. Thus, a repeated track record of withdrawing from syndicates can create a global signal of unreliability that can affect all prospective syndication partners.

Venture capitalists are acutely aware that their withdrawal decisions can affect their overall reputation and access to future syndication partners. As one VC firm principal volunteered, “[you] want a VC who is a good partner, who would stick to the company through thick and thin...Most of us work with other VCs at some point, so it is very bad to develop a reputation for being a bad partner” (emphasis added). Another VC echoed this sentiment, “[It] is critical to support the company in good times and bad, and the partners who withdraw from the syndicate at the first signs of bad news are often not so much sought after.”

We therefore propose in Hypothesis 2 that withdrawals can be considered a globallyobservable, reputation-impairing event that can reduce the attractiveness of a particular VC to all prospective syndication partners:

Hypothesis 2: A focal VC firm will be less likely to syndicate with alters that have withdrawn from a larger proportion of their syndicates.

\section{The Local Reputational Consequences of Withdrawal}

A global reputational perspective assumes that all relevant information about the alter is universally accessible and sufficiently salient to all participants in the system. This is a common assumption within much of the research on corporate reputation. For example, studies examining the link between reputation and organizational characteristics (such as financial performance or good citizenship behavior) typically assume that the entire polled audience was aware of all such characteristics (e.g., Fombrun \& Shanley, 1990). While such public information has the advantage of comprehensiveness and ease of accessibility, scholars have increasingly recognized that much of the reputation-relevant information can only be obtained through private contacts 
and thus may be only accessible to actors with the right connections (Hillmann \& Aven, 2011; Raub \& Weesie, 1990).

In our context, the indirect connections of a focal VC firm to the prospective alters via a shared syndication partner are likely to be especially important for the due diligence process for two major reasons. First, a shared syndication partner is likely to have first-hand information about both the prospective alter and inside details of the collaboration. For example, conversations with principals from VCs abandoned by a prospective alter can provide rich details of what happened behind closed doors. This is information that is unlikely to be available in the public record, yet it is important for making sense of the reasons behind a withdrawal and the likelihood that the alter will withdraw from future collaborations. Second, syndication partners are purportedly trustworthy data providers. Intense collaborations are conducive to the development of deep, trust-based relationships that facilitate the transmission of sensitive private information (cf. Gulati, 1995a, 2007; Uzzi, 1997). Furthermore, private contacts are considered a credible source of information, because they put their own reputation at risk (Gulati \& Gargiulo, 1999: 1447). The venture capitalists with whom we talked were acutely aware of the reputational costs of misrepresentations. As one noted, "It is a small world, and if someone lies to you, it will come back to bite them in the end.”

Shared syndication partners can therefore serve as a trusted source of rich, private information about the prospective alter. Existing research has largely assumed that such information would generally allay the focal firm's concerns about collaborating with the alter and increase the probability of forming a direct relationship between them (Gulati, 1995b; Gulati \& Gargiulo, 1999). We depart from this implicit assumption by proposing that the private information flowing across the indirect ties is not necessarily positive, and its valence will be 
shaped by the experiences of the shared partner with the alter. As we argued in our motivation for Hypothesis 1, experiencing a withdrawal can lead the abandoned actor to question the reliability of the alter; such negative attributions can be reinforced further by the relationship breakdown that can accompany the withdrawal. As a result, the abandoned former syndication partners of the alter are more likely to pass on negative information to their own network contacts, reducing the likelihood that they would engage in syndication with the withdrawing party. ${ }^{6}$ This leads us to propose Hypothesis 3:

Hypothesis 3: A firm is less likely to syndicate with an alter if it has more connections to abandoned syndication partners of the alter.

\section{Local and Global Reputational Consequences of Withdrawal}

Our argument so far has proposed two distinct reputational consequences of withdrawal. The global reputational consequences are caused by the public information on an alter's history of withdrawals, which serves as a negative signal that affects all VC firms considering a syndication partner. The local reputational consequences are driven by negative private information, which spreads only to those with connections to the abandoned coinvestors. Although a significant body of work has touched on these two separate mechanisms—global reputation engendered by an overall track record of behavior (e.g., Dollinger et al., 1997; Rao, 1994; Sullivan et al., 2007) and transferring private information across interorganizational ties (Gulati \& Gargiulo, 1999; Shane \& Cable, 2002) — there is little understanding of how these two mechanisms interactively affect tie formation behavior.

\footnotetext{
${ }^{6}$ Although we do not formally formulate it as a hypothesis, we fully expect that connections to non-abandoned former coinvestors of the alter will increase the likelihood of syndication. Because our empirical strategy rests on disaggregating the connections to abandoned and non-abandoned syndication partners, we will have the opportunity to compare the two coefficients directly.
} 
We propose that simultaneous access to both public and private information about an actor's past withdrawals can shape the behavior of recipients of that information in ways in which each is amplified by the presence of the other. A firm's exposure to negative private information about an alter can magnify the effect of negative public information via two key mechanisms. First, cognitive limitations in the way we look at large bodies of information means that private information can increase the salience of similar publicly available information. Organizational actors are attention constrained and generally attend to only a fraction of all the information to which they are exposed (Ocasio, 1997). When faced with information overload, they tend to zero in on information related to what they already know (Piezunka \& Dahlander, 2015). Private information tends to be vivid and easy to retain, especially when it is shared in person and is drawn from the interlocutor's first-hand experience (Nisbett \& Ross, 1980). As a result, private information can form the cognitive filter through which venture capitalists selectively process the much larger sea of publicly available information. Similar explanations have been proposed in other settings; for example, Haunschild and Beckman (1998: 840) argued that business press coverage of acquisitions focuses attention on the M\&A activities of a company’s interlock partners and thus increases their influence on decision-making.

Second, we know that when actors receive supportive information from multiple sources, they tend to believe that the information is more credible (cf. Stern, Dukerich, \& Zajac, 2014). In our context, this means that negative private information and negative public information can enhance one another's credibility when they offer a convergent view of an actor. Private information provides richer inside details that allow compelling sense-making around a small number of cases; in contrast, public information covers an entire track record of behavior, but gives few of the rich details needed to translate the raw facts into a character assessment. When 
exposed simultaneously to consistently negative public and private information, recipients of that information have greater confidence in drawing negative inferences about the prospective alter and generalizing those inferences to the alter's entire track record.

Together, the two mechanisms support our fourth hypothesis:

Hypothesis 4: The negative effect of an alter's history of withdrawals on the probability of syndication with a focal VC firm will be stronger if the focal VC firm has more connections to abandoned syndication partners of the alter.

Figure 1 provides an overview of our hypotheses. Hypotheses 1 looks at the relational consequences of withdrawals; that is, a focal VC firm is less likely to syndicate with an alter that has previously withdrawn from one of its syndicates. Hypothesis 2 examines the global reputational consequences of withdrawal and predicts that a focal VC firm will be more averse to syndicating with an alter that has withdrawn from a greater proportion of its prior syndications. Hypothesis 3 proposes that a focal firm’s connections to previously abandoned syndication partners of the alter will reduce the likelihood of syndication. Finally, Hypothesis 4 predicts that a focal firm's connections to previously abandoned syndication partners of the alter will reinforce the negative effect of the alter's proportion of past withdrawals on the likelihood of syndication.

Insert Figure 1 about here

\section{Data Source}

\section{DATA AND METHODS}

Our core data were drawn from Thomson Reuter's VentureXpert database, which has tracked venture capital fundraising, investments, and exits since the 1970s. VentureXpert is used 
widely for research in both finance (Hochberg et al., 2007, 2010) and economic sociology

(Podolny, 2001; Sorenson \& Stuart, 2001, 2008). Our data cleaning process entailed several steps. To focus on the dynamics of the US venture capital market, we excluded all non-US VC firms and investments. We also eliminated entities that VentureXpert had not identified as dedicated venture firms, ${ }^{7}$ and we eliminated funds that had made no investments over the preceding 5-year period.

Identifying withdrawals was a critical step in the data cleaning. Following Townsend (forthcoming), we defined a withdrawal as the permanent disappearance of a VC firm from the ranks of coinvestors. If a firm merely skipped a round but renewed participation at a later point, we continued to count it as a syndicate participant. We did this for two reasons. First, some of the omissions were apt to be due to data errors. Second, even if a firm indeed failed to participate in an investment (i.e., due to liquidity issues), its readmission suggested that it was granted a temporary reprieve by its coinvestors. When none of the original members of a syndicate participated in a follow-up round_-for example, if they were bought out by another syndicatethey were not counted as withdrawing. In cases of a complete change in syndicates, we simply stopped tracking that particular company. Finally, we did not include withdrawals following a successful exit such as an IPO or acquisition.

\footnotetext{
${ }^{7}$ In particular, such criterion excludes Corporate Venture Capital (CVC), the venture arm of major corporations. We made this decision for two reasons. First, CVCs typically invest primarily for strategic reasons (such as access to technology) rather than financial reasons (such as bringing the company to IPO). Their incentives often include acquiring crucial resources of the portfolio company at the lowest price; thus, they can be misaligned with the entrepreneur's or the other VC investors' objectives (Hallen, Katila, \& Rosenberger, forthcoming; Katila, Rosenberger, \& Eisenhardt, 2008). Second, CVCs syndicate less frequently (Hochberg et al., 2010), in part because as sole investors, they can have stronger control over the portfolio company and its resources. For these and other reasons, excluding CVCs from analyses of VC syndication is common practice (Hochberg et al., 2007; Sorenson \& Stuart, 2001, 2008; Trapido, 2007).
} 
A possible concern with our coding of withdrawals is that it does not distinguish prenegotiated withdrawals in which a VC committed to participate solely in an early round-and thus exits with the prior approval of its coinvestors - from withdrawals that happened over the coinvestors' objections. The former scenario is especially likely if a particular firm's strategy focuses primarily on early stage investments. Although it is difficult to reconstruct systematically the reasons a firm has withdrawn from a syndicate based on the archival data, we made several efforts to grapple with the following possible alternative rationale for exit. ${ }^{8}$ First, if certain firms withdraw as a matter of strategy, then we expect that they will have withdrawn from a large proportion of their syndicates. In our sensitivity analyses, therefore, we excluded all firms belonging to the top decile in terms of overall withdrawal rate (i.e., have withdrawn from more than $35 \%$ of their syndicates). Second, because the tendency to engage in pre-negotiated exits is likely to be a part of a firm's long-term strategy—and thus relatively time-invariant ${ }^{9}$ — we also explored in our robustness checks whether adding firm fixed effects would change our main results. Finally, it bears emphasizing that any pre-negotiated withdrawals that are not controlled for in our two robustness tests will likely bias our estimates of the reputational and relational consequences of withdrawal toward zero and therefore make our results more conservative.

Our aim was to identify the individual- and relationship-level factors that drive the probability of a given pair of active funds establishing a connection in a given year. In setting up our dyadic dataset, we first created all possible dyads of firms active in a given year. To eliminate spurious pairs, we examined only pairs that invested in the same industry and the same

\footnotetext{
${ }^{8}$ We are grateful to an anonymous reviewer for bringing this point to our attention.

${ }^{9}$ Generally, firm investment strategies are fixed in the investment prospectus and are therefore relatively stable during the 10-year life of the fund.
} 
geographic region during the focal year. Using this approach, we found approximately 1.2 million potential pairs, approximately 41,000 of which were actually realized. Analyzing all these observations, however, led to autocorrelation, because each firm is represented in a large number of counterfactual pairings. It also led to low variance of the dependent variable, which biases the coefficients in logit and probit models (Jensen, 2003; King \& Zeng, 2001; Trapido, 2007). We then followed standard practice by taking a random sample of the unrealized dyad years to achieve a 5:1 ratio of realized to unrealized observations (Jensen, 2003; Sytch \& Tatarynowicz, 2014b). This resulted in a final dataset of 250,730 observations. Following Jensen (2003), we also ensured that all our results were robust to ratios of 3:1 and 10:1 of controls to cases.

The present study's dataset is based on unique dyads; that is, the specification of one firm as the first member of the dyad and the other as the second member is determined randomly and consistent throughout all annual observations of the pair. The ordering of the firms in the dyad made no difference for any of the variables. The dyadic attributes (such as the distance between the two investment portfolios or the number of prior connections) are independent of ordering, and the node-specific attributes (such as centrality or the number of times one member of the dyad has withdrawn from the other's syndicates) were summed and presented as a single coefficient following standard practice (Gulati \& Gargiulo, 1999; Stuart, 1998; Trapido, 2007). ${ }^{10}$

\footnotetext{
${ }^{10}$ The justification for summing all node-specific attributes is as follows. Let $Y_{\mathrm{ij}}$ be the dyadic outcome of interest for actors $i$ and $j$; $\boldsymbol{X}_{\mathrm{i}}$ is the vector of node-specific attributes for actor $i ; \boldsymbol{X}_{\mathrm{j}}$ is the vector of node-specific attributes of actor $j$; and $\boldsymbol{X}_{\mathrm{ij}}$ is a vector of dyadic attributes. $\mathrm{Y}_{\mathrm{ij}}$ is predicted by these three vectors, therefore,$$
\mathrm{Y}_{\mathrm{ij}}=\mathrm{f}\left(\boldsymbol{b}_{1} \boldsymbol{X}_{\mathrm{i}}+\boldsymbol{b}_{2} \boldsymbol{X}_{\mathrm{j}}+\boldsymbol{b}_{12} \boldsymbol{X}_{\mathrm{ij}}\right)
$$

Because the order of the firms is determined randomly, and the dependent variable $Y_{\mathrm{ij}}$ is symmetric (i.e., $Y_{\mathrm{ij}}=\mathrm{Y}_{\mathrm{ji}}$ ), the monadic attributes of each firm in the dyad should have equal effect on the dependent variable, that is, $\boldsymbol{b}_{1}=\boldsymbol{b}_{2}=\boldsymbol{b}$. Substituting in the equation shows that we can obtain the coefficient vector b by summing the monadic attributes:

$$
\mathrm{Y}_{\mathrm{ij}}=\mathrm{f}\left(\boldsymbol{b} \boldsymbol{X}_{\mathrm{i}}+\boldsymbol{b} \boldsymbol{X}_{\mathrm{j}}+\boldsymbol{b}_{12} \boldsymbol{X}_{\mathrm{ij}}\right)=\mathrm{f}\left(\boldsymbol{b}\left(\boldsymbol{X}_{\mathrm{i}}+\boldsymbol{X}_{\mathrm{j}}\right)+\boldsymbol{b}_{12} \boldsymbol{X}_{\mathrm{ij}}\right)
$$
}


To test Hypotheses 4a and 4b, which require the interaction between each firms' social overlap with the abandoned coinvestors of the alter on the one hand, and the overall withdrawal rate of the alter on the other hand, we first computed the product of the two variables (mean-centered to avoid multicollinearity issues) from the perspective of each firm, and then summed it across the dyad.

\section{Variables}

Dependent variable. To test our hypotheses, we chose an indicator equal to 1 if the two firms jointly invested in their first round via a syndicate during the focal year (labeled Coinvestment in the data tables). We explicitly ignored continued coinvestment; if the two firms coinvested in a given company in 1990 and continued to do so in follow-up rounds in 1991 and 1992, we only counted 1990 as a "real" coinvestment. Our reasoning is that the crucial decision to collaborate is made at the outset, and because subsequent coinvestments are largely assumed and entail a high exit cost. We also decided to use a dichotomous indicator rather than a count variable due to the very small number of multiple joint investments in the same year.

Another overarching question was "the statute of limitations" on past behavior; that is, how soon do prior investments and connections lose their relevance to the present? We followed established practice in the study of VCs (e.g., Sorenson \& Stuart, 2001; 2008) and used a 5-year sliding window for all network variables: connections, centrality, and withdrawals. This decision is justified by the typical 5-year lifespan of a venture capital transaction. The portfolio of deals over this timeframe defines the totality of active, ongoing connections. Because scholars have expressed concerns about the reliability of VentureXpert data prior to 1980 (e.g., Podolny, 2001), 
we used data from 1980 to 1984 to create the network for 1985 and excluded all earlier dyadyears.

Independent variables. The core independent variables focus on the withdrawal behavior of VC firms. To test Hypothesis 1, we created the variable Direct Withdrawal $i$, equal to the number of times firm $i$ withdrew from syndicates in which firm $j$ continued participating in the prior five years to that dyad-year, divided by the overall number of unique syndicates between the two. Because withdrawals are node-specific, we summed the two values of the variable associated with both firms (Direct Withdrawal Rate).

To test Hypothesis 2, we calculated each VC firm's overall number of withdrawals over the preceding five years and divided it by the total number of unique syndicates in which it had participated (Overall Withdrawal Rate). The mean for the variable is about 14\%, but it hides a significant amount of dispersion. Slightly more than 30\% of firms had never withdrawn from a syndicate in the preceding five years, and more than half had withdrawn from fewer than $10 \%$ of their syndicates. On the high end, about $10 \%$ of firms had withdrawn from one-third or more of their syndicates. Such variability means that withdrawal behavior can be used readily as a means to identify potentially unreliable partners. In our empirical analysis, we summed the overall withdrawal rate of the two firms in the dyad, as we did with the other node-specific variables.

For Hypothesis 3, we need to distinguish between the each firm's ties to the abandoned and non-abandoned partners of the alter. We first created an overall Social Overlap measure of the shared ties between the two firms by constructing a Jaccard index of their partner sets (Jaccard, 1901). Conceptually, this measure standardizes the number of shared partners of the two firms by the number of non-shared partners into an index ranging from zero (if they have no 
shared partners) to one (if all of their partners are shared). It is preferable to a straight count of shared partners, because the latter can be heavily correlated with the actors' overall degree of centrality (e.g., Srivastava, 2013).

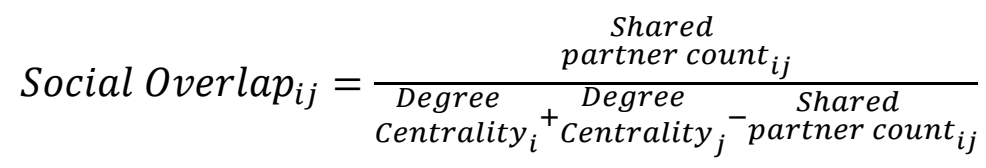

We then separately calculate the social overlap of each of the firms with the abandoned and the non-abandoned partners of the alter. This measure can be different for the two firms in each dyad (e.g., the one firm in the dyad may not have connections to any of the firms that the alter has abandoned, whereas the alter might have connections to multiple firms that the first firm has abandoned) and therefore has to be summed as any of the node-specific variables.

Social Overlap to Abandoned $_{i j}=\frac{\text { Count of ties to }^{\text {abandoned }}{ }_{i j}}{\text { Centrality }_{i}{ }^{+} \text {Dentrality }_{j}{ }^{- \text {Count of ties to }_{\text {abandoned }}{ }_{i j}}}$

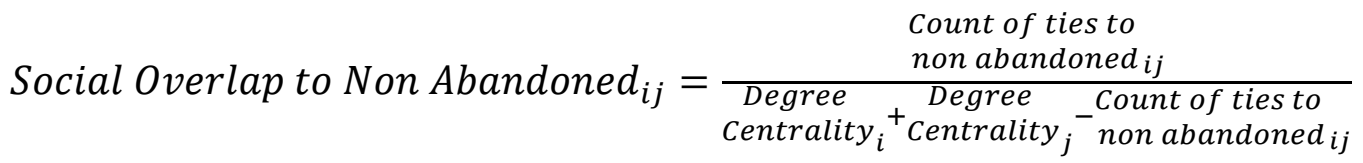

Control variables. In addition to the main effects of the variables described, we incorporated several additional controls to address alternative explanations and potential concerns of endogeneity. First, we wanted to include a measure of the historical investment activity of each firm in the dyad. We represented this by the summed number of investments each of the firms made over the preceding five years. Second, we incorporated the summed degree centrality of each of the firms in the interorganizational network, which in other settings has been found to strongly predict tie formation behavior (Gulati \& Gargiulo, 1999). The two 
measures, however, were highly correlated (above $80 \%$ correlation); thus, we retained only the summed centrality measure within the analysis to alleviate any multicollinearity concerns within our models. Our substantive results are not sensitive to whether we use just the investment count or both variables together.

We were very mindful of possible endogeneity concerns posed by variables that may increase the probability of withdrawals and independently reduce the attractiveness of the focal VC firm. One set of such variables is the capital availability to the focal VC firm. Firms that are more capital-constrained are more likely to withdraw from syndicates, because they are running out of capital to contribute. They are similarly less attractive to exchange partners because they cannot guarantee follow-on financing (Piskorski \& Anand, 2011; also per author interviews). We operationalized capital constraints with two variables, both summed across each firm in the dyad. We first measured the percentage of the most recent fund that each firm had already invested. If this ratio was high, this means that a firm is running out of capital to continue participating in existing syndicates or to commit to new ones. We also included the age of the most recent fund of each firm in the dyad (logged to reduce the influence of outliers) to represent its stage in the fund lifecycle. Successful VC firms typically raise a new fund every two to three years; failure to raise funds over a longer horizon may signal fundraising troubles (Kaplan \& Schoar, 2005). Firms that have very mature funds may want to preserve capital by not committing additional funds to existing syndicates or to new ones. At the same time, they are less attractive because their syndication partners might doubt their fundraising and follow-on capability. Fund information was unavailable for some observations ( $\sim 15 \%$ of the total). For these instances, we introduced a dummy variable and imputed sample average values for fund age and percentage 
invested. Both the present funding-constraint variables and the missing fund dummies were incorporated into the model as controls.

We also incorporated several dyadic controls that prior research has demonstrated to be highly predictive of dyadic matching. One major determinant of the likelihood of coinvestment is the similarity of investment specialization across industries and geographies; similarly specialized VCs are more likely to be interested in the same portfolio companies and thus more likely to encounter each other (cf. Trapido, 2007). We operationalized Industry Specialization Distance based on Sorenson and Stuart's (2008) Euclidean distance measure. Specifically, we used a 10-industry categorization scheme adapted from Gompers, Kovner, and Lerner (2009) that aggregates the more finely grained VentureXpert classification into 10 broad industry categories (e.g., Biotech and Healthcare, Electronics, Internet and Computers, Energy, etc.). For each firm, we then calculated a 5-year trailing percentage of deals made in each industrial category. We then calculated the Euclidean distance between two specialization vectors as follows ( $p_{j l}$ represents the proportion of VC firm $j$ 's investments into industry sector $l$ ):

$$
\text { Industry Specialization Distance } e_{i j}=\sum_{l=1}^{10}\left(p_{j l}-p_{i l}\right)^{2}
$$

We similarly calculate a State Specialization Distance based on the geographic location of the portfolio companies of each VC in the dyad. Specifically, for each firm we construct a 52dimensional vector containing the proportion of their investments in each state plus the District of Columbia and Puerto Rico. We then calculate the Euclidean distance between the two vectors per the same formula ( $p_{j l}$ represents the proportion of VC firm $j$ 's investments into state $l$ ):

$$
\text { State Specialization Distance } e_{i j}=\sum_{l=1}^{52}\left(p_{j l}-p_{i l}\right)^{2}
$$


Our final dyadic control is geographic distance between the two VCs, because geographically proximate VCs are more likely to engage in syndication (cf. Sorenson \& Stuart, 2008). We calculated Geographic Distance using average distance in miles between the geographic coordinates of the ZIP codes of the two firms' headquarters, and then logging it to reduce overdispersion using the same procedure as Sorenson and Stuart (2001).

\section{Methods}

The core analyses were conducted using a logit model, where the probability of both members of the dyad coinvesting together is modeled as:

$$
P(t)=\mathrm{L}\left(a+b X_{i j}+c Y_{i j}(t)\right)
$$

where $\mathrm{L}$ is the logistic function; $\boldsymbol{a}, \boldsymbol{b}$, and $\boldsymbol{c}$ are vectors of parameters to be estimated; and $\boldsymbol{X}_{\boldsymbol{i} \boldsymbol{j}}$ and $\boldsymbol{Y}_{i j}(\boldsymbol{t})$ are the dyad-specific vectors of time-invariant and time-variant variables, respectively.

To account for the rare events nature of syndication data, we used the rare events corrections implemented by King and Zeng (1999b; 2001) as the relogit command in STATA. This method alleviates the tendency of logistic models to underestimate the likelihood of very low-probability events and the bias arising from oversampling factual versus counterfactual observations. Many recent studies have used a similar approach in analyzing tie formation in a variety of settings, including venture capital syndication (Rider, 2012; Trapido, 2007), strategic alliances (Sytch \& Tatarynowicz, 2014b), and investment bank advising relationships (Jensen, 2003).

A typical challenge with such models is that they do not necessarily account for dyadic dependence; that is, the influence of unobserved variables of the individual firms that carry over 
to all the observations in which they participate. We addressed this issue in two ways. First, we controlled for the Lincoln Autoregressive Term, first proposed by Lincoln (1984) and frequently used to alleviate dyadic autocorrelation in tie formation studies (Rider, 2009; Stuart, 1998; Sytch \& Tatarynowicz, 2014b). It is based on the mean value of the dependent variable across all dyads involving either of the VCs in the dyad for the focal year, but excluding the focal dyad. This variable captures the raw level of syndication activity of both sides of the dyad in a given year and purges our results of period-specific, unobserved heterogeneity in the syndication likelihood of the two firms in the dyad. Second, in the presence of dyadic dependence, clustering merely by dyad would underestimate the actual correlation structure of the error terms and lead to inconsistent standard error estimates. Several solutions exist; we adopted the multiple clustering algorithm proposed by Cameron, Gelsbach, and Miller (2011) and implemented in STATA by Kleinbaum, Stuart, and Tushman (2013) as the clus_nway package. We clustered by both members of the dyad and by year, resulting in seven discrete clusters: 1) Firm 1; 2) Firm 2; 3) year; 4) Firm 1 and year; 5) Firm 2 and year; 6) Firm 1 and Firm 2; and 7) Firm 1 and Firm 2 and year. The algorithm combines the results of each of the seven clusters into a single, robust estimate.

Finally, we addressed the issue of potential unobserved heterogeneity—specifically, the extent to which a track record of withdrawals is correlated with unobserved variables that may independently reduce the attractiveness of the VC firm. We included measures of the financial resources of the focal firm, because scarce resources can trigger withdrawals, while simultaneously reducing the attractiveness of the VC firm (Piskorski \& Anand, 2011). We also included year fixed-effects in all models to account for the dramatic swings in VC activity across time, which has been documented in prior research (Gompers \& Lerner, 2000; Gompers \& 
Lerner, 1999). We also conducted robustness tests using fixed effects for each of the firms in the dyad to rule out time-invariant, unobserved heterogeneity.

Note as well that although the present paper is based primarily on quantitative data, during the course of the project, we conducted seven formal interviews with VC principals and multiple informal interviews with venture capitalists at varying levels of seniority. To a large extent, their comments about the importance of the perceived reliability of the exchange partner inspired our research question. These interviews were important for shedding light on some of the mechanisms at play such as the financial circumstances of the VC firms and for refining our measures and controls for our quantitative analyses.

\section{RESULTS}

Table 1 presents the univariate descriptive statistics and the correlation matrix for the final dataset. Realized observations account for approximately $17 \%$ of the total due to random sampling of counterfactuals (one realized value for every five unrealized values). All variables with potential for highly skewed distributions (such as centrality and geographic distance) have been logged to yield better-behaved distributions. Note that the variables representing node characteristics (such as centrality, withdrawal rate, and the social overlap with the alters abandoned/non-abandoned partners) have been summed across both sides of the dyad; therefore, the sample averages for the individual firms are approximately half of the reported values. Also, we have reported the uncentered means of all the independent variables, even though we centered them before computing the interactions.

The correlations between the main independent variables (direct withdrawals and withdrawal rates) and the likelihood of syndication are positive, but part of this relationship is 
clearly driven by other variables. For example, the correlation of direct withdrawals with syndication probability is confounded by the high correlation of both variables with the total number of past syndication ties within the dyad. The control variables have the expected correlations with the probability of syndication. Prior syndication experience, a higher number of shared partners, and greater industry and state specialization overlap are all associated with the higher probability of syndication. This is consistent with past research (Sorenson \& Stuart, 2001, 2008; Trapido, 2007). Some other independent variables also appear highly correlated in the direction that one might expect. For example, the direct withdrawal rate is significantly correlated with the number of prior ties (64\%), because no direct withdrawals are possible if no prior tie between the two VC firms in the dyad existed. Similarly, degree centrality is $62 \%$ correlated with the social overlap with alter's partners; that is, more central firms are more likely to have ties with any other VC firm. Not surprisingly, the two controls measuring the financial health of the firms - percentage of capital invested and age of the most recent fund-are also significantly correlated at about 50\%. Finally, social overlap with the non-abandoned partners of the alter is more than $90 \%$ correlated with overall social overlap; however, those two variables never enter the same regression equation together. To ensure that multicollinearity is not an issue, we ran diagnostics on all models reported on Table 2. The maximum variance inflation factor (VIF) is around 3.1, which is significantly below the maximum suggested limit of 10 (Kutner, Nachtsheim, \& Neter, 2004). Also, omitting individual control variables does not substantively affect the results.

Insert Table 1 about here 
The main analyses are presented in Table 2 . Model 1 presents the baseline model predicting tie formation, with results similar to other studies of syndication (Sorenson \& Stuart, 2001, 2008; Trapido, 2007). Consistent with the expectations of network theorists, a firm’s prior number of ties and larger social overlap with the alter's past partners are associated with a higher probability of syndication (Gulati, 1995b). Firms also tend to syndicate with those who are geographically close or share similar investment specialization (Sorenson \& Stuart, 2001; Trapido, 2007). Finally, a firm’s financial resources-measured by having recently raised a fund-increase its attractiveness to coinvestors.

Insert Table 2 about here

Model 2 shows that a firm is less likely to syndicate with alters who have previously abandoned it, thus providing support for Hypothesis $1 .{ }^{11}$ For a pair with one prior deal from which one of the partners withdrew, the probability of syndication between them falls by approximately 17\%. Model 3 adds the overall proportion of withdrawals and shows that firms are less likely to enter into syndicates with alters that have withdrawn from a higher proportion of their syndicates; this finding is consistent with Hypothesis 2. At average values across the sample, an increase of one standard deviation on the overall withdrawal variable yields a reduction in the likelihood of syndication from approximately $2.3 \%$ to $2.1 \%$, or about $10 \%$ of the base rate.

\footnotetext{
11 The results are consistent whether we use the proportion or the count of the pair's syndicates that have resulted in a withdrawal.
} 
In Model 4, we disaggregate overall social overlap with the alter's past coinvestors into social overlap with the abandoned coinvestors and social overlap with the non-abandoned coinvestors. Connections to non-abandoned coinvestors of the alter increase the likelihood of syndication, which is consistent with much of the existing network research. However, connections to abandoned coinvestors of the alter-who are likely to be passing on negative private information — inhibit syndication. These findings provide support for Hypothesis 3 and our argument for the local reputational consequences of withdrawal. ${ }^{12}$

Figure 2 illustrates the effects of the focal firm’s social overlap with the abandoned and the non-abandoned partners of the alter. ${ }^{13}$ Assuming there are no ties to non-abandoned syndication partners of the alter, an increase in the social overlap with abandoned partners of the alter by one standard deviation from zero reduces the likelihood of syndication from a baseline of $1.8 \%$ to $1.7 \%$, for a change of approximately $6 \%$. Although this decrease is substantively small, it should be considered in the context of the small variance of this variable due to the rarity of withdrawals, as well as the strong null established by prior research that connections to shared partners should increase the likelihood of syndication.

Conversely, an increase in the social overlap with the alter's non-abandoned coinvestors by one standard deviation from zero increases the likelihood of syndication from $1.8 \%$ to $2.3 \%$, for an increase of approximately 27\%. The results make it clear that ties to abandoned

\footnotetext{
12 The results are robust whether we use the social overlap measures (which implicitly standardize for the centrality of the two VCs in the dyad) or simpler measures, such as logged count of ties to abandoned/non-abandoned syndication partners of the alter.

${ }^{13}$ All the charts are produced based on the rare event logit reported in Model 6, Table 2, and using the relogitq STATA package developed by King and Zeng (1999a, b). It simulates the rare event logit parameters based on the point estimates and the covariance matrix and uses those values to estimate the predicted probabilities under various scenarios.
} 
coinvestors have dramatically different effects than ties to non-abandoned coinvestors, presumably because of the different valence of the information being passed along.

Insert Figure 2 about here

Finally, Model 5 examines the interaction between the local and global reputational consequences of withdrawal. It shows that connections to the abandoned coinvestors of the alter attenuate the negative effect of the alter's overall history of withdrawals on the likelihood of syndication. This finding runs counter to the expectation of Hypothesis 4 and the idea that negative private information can focus attention on, and increase the credibility of, negative public information. Instead, the results are consistent with a redundancy mechanism: the idea, well established in learning theory, that "information from multiple sources has a substitutional effect if these sources provide redundant or duplicate information” (Schwab, 2007: 238). In other words, there are diminishing marginal returns to information of the same type. If the private information obtained through social connections persuades a focal firm that a given alter is unreliable, negative information from the public record will matter less in the decision not to collaborate with that alter. We elaborate on the implications of this finding in the Discussion.

Model 5 also shows that ties to non-abandoned coinvestors of the alter magnify the negative effects of the alter's history of withdrawal on the likelihood of syndication. This provides further evidence against the logic underlying Hypothesis 4; that is, if we take its attention and credibility enhancements arguments at face value, we would expect that exposure to positive information from non-abandoned coinvestors of the alter would reduce the salience and importance attributed to the alter's withdrawals in the public record. Instead, what we observe suggests that firms do not take advantage of the syndication opportunities created by 
shared partners when they are concerned about the reliability of the prospective alter based on negative public information about them.

We graphically depict in Figures 3 and 4 the substantive effects of the interactions. Figure 3 examines how a focal firm's social overlap with abandoned coinvestors of the alter moderates the effects of the alter's overall history of withdrawals. ${ }^{14}$ If the focal firm has no social overlap with prior coinvestors of the alter, a one standard deviation increase in the alter's withdrawal rate decreases the likelihood of syndication from $2.4 \%$ to $2.2 \%$, for a decrease of approximately $8 \%$. In contrast, at a higher level of overlap with the abandoned investors of the alter (mean plus one standard deviation), a one standard deviation change in the alter's withdrawal rate decreases the likelihood of syndication from $2.3 \%$ to $2.2 \%$, for a decrease of approximately $4 \%$. The two curves cross at an alter withdrawal rate of approximately .27, which is within the observed range (approximately the 85\% percentile).

Insert Figure 3 about here

In Figure 4, we also present the extent to which the effects of the alter's prior history of withdrawals are moderated by the focal firm's social overlap with its non-abandoned partners. When the focal firm has no connections to the alter's non-abandoned coinvestors, the alter's withdrawal rate has virtually no effect on the likelihood of coinvestment. In contrast, at a high level of overlap (mean plus one standard deviation), one standard deviation increase in the alter's

\footnotetext{
${ }^{14}$ Note that we vary only the alter's withdrawal rate and the focal firm's social overlap with its partners; the focal firm's own withdrawal rate, and the alter's social overlap to the focal firm's abandoned or non-abandoned partners are kept at mean values. The mean withdrawal rate on only one side of the dyad is 0.13 , and the standard deviation is 0.17. Similarly, the mean social overlap with the abandoned coinvestors of the alter is 0.01 (standard deviation of 0.03 ) and the mean social overlap with the non-abandoned coinvestors of the alter is .07 (standard deviation of .08).
} 
withdrawal rate diminishes the likelihood of syndication from $3 \%$ to $2.6 \%$, that is, a $14 \%$ decrease.

Insert Figure 4 about here

Robustness tests. We conducted several analyses to verify the robustness of these findings. The results are stable if we exclude serial withdrawers (the top 10\%), which may have anticipated and prenegotiated their withdrawals. We verified the robustness of the models with respect to alternative measures, such as logged count of shared partners in place of the Jaccard index to measure the social overlap; logged Bonacich centrality in place of degree centrality; and a dummy variable instead of a proportion to measure the presence of direct withdrawals within the dyad. Furthermore, we tested the robustness of the results to alternative measures of the dependent variable, by only considering syndications in which one of the members of the dyad was a lead investor. ${ }^{15}$ In addition, we verified the robustness to different draws of the counterfactuals and to different ratios between factual and counterfactual observations; that is, in addition to the default 1:5 ratio, we also tested a 1:3 and 1:10 ratio (Jensen, 2003).

Studies of dyadic tie formation based on the rare event logit framework do not typically employ node-level fixed effects, relying instead on the autoregressive constant to absorb the unobserved heterogeneity in tie formation proclivities of each side of the dyad (Rider, 2012; Sytch \& Tatarynowicz, 2014b; Trapido, 2007). Because the overall track record of withdrawala key explanatory variable in our model — is a monadic variable, however, we wanted to ensure

\footnotetext{
${ }^{15}$ We define lead investor based on the highest cumulative investment in the portfolio company, which is consistent with Sorenson and Stuart's (2008) definition. We allowed ties if two VCs have equal shares in the portfolio company.
} 
that our results are not biased by unobservables that simultaneously drive the likelihood of withdrawal and the overall proclivity for syndication. We have already included the financial situation of the two VCs, a key time-varying driver of both withdrawals and syndication activity, as a control. To rule out the effects of time invariant-heterogeneity (e.g., long-term firm strategy to both withdraw often and be more selective about syndications), we incorporated firm-level fixed effects for all 1,812 firms in our model. The rare event logit could not handle this many additional covariates; therefore, we used a normal logit—reweighted to reflect the undersampling of control cases-to conduct the fixed-effect analyses. The effects were similar to those reported; the only substantive difference was that the social overlap with the alter's abandoned syndication partners lost its statistical significance. Although it was not distinguishable from zero, it remained statistically different from the social overlap with non-abandoned syndication partners of the alter.

Post hoc analyses: Alternative channels of information diffusion. We considered alternative channels through which negative, private information from the abandoned coinvestors of the alter can reach the focal firm even in the absence of formal syndication ties. It is likely that venture capitalists are more likely to maintain informal connections to other firms that are 1) similar to them in terms of investment specialization or 2) geographically proximate. In unreported analyses, we constructed alternative proxies of the focal firm's access to the alter's abandoned coinvestors. These included 1) the number of the alter's abandoned coinvestors that are close in industry specialization to the focal firm $\left(10^{\text {th }}\right.$ percentile or less in industry specialization distance) and 2) the number of abandoned coinvestors of the alter that are within close geographical proximity to the focal firm (50 miles or less). We used these two proxies to replace the social overlap with abandoned syndication partners of the alter to retest Hypotheses 3 
and 4. Consistent with our main results, both proxies reduce the likelihood of syndication and attenuate the negative effects of overall withdrawals on the likelihood of syndication. However, both of those measures are completely dominated by the social overlap variables when included in the same equation, suggesting that direct syndication ties are the primary mechanism of diffusing reputational information.

We also examined whether negative information from the abandoned coinvestors of the alter can reach the focal firm via one or more intermediaries in addition to direct syndication ties to the abandoned coinvestors. We constructed additional measures of social overlap with past abandoned and non-abandoned partners of the alter over path lengths of two, three, or four connections. We found that connections of the focal firm to abandoned and non-abandoned coinvestors of the alter have a statistically different effect only in the case of direct syndication ties of the focal firm to those actors. In other words, the content of the information originating from past coinvestors of the alter gets completely swamped by noise as it travels through one or more intermediaries.

Post hoc analyses: Circumstances of the withdrawal. In another set of post hoc analyses, we investigated whether the circumstances of the withdrawal might affect our results. In particular, we investigated whether the consequences of withdrawals differed depending on whether the syndicate from which the focal VC withdrew was successful (i.e., the portfolio company the syndicate supported went public or was acquired by a strategic investor) or unsuccessful (i.e., the portfolio company went bankrupt). Theoretically, we expected that the failure of the abandoned syndicate may soften reputational damage, because it would provide an ex post justification for the withdrawal decision. However, we did not see any moderating effect of the syndicate's outcome on either the relational or the reputational consequences of 
withdrawal. There are several explanations for this finding. First, the outcome of the portfolio company can manifest itself after several years. The outcome is thus uncertain in the immediate years following the withdrawal, when the relational and reputational consequences are likely to be the strongest. Second, the ex post outcome is subject to different interpretations that cannot be fully disentangled here and are beyond the scope of the present study. For example, a portfolio company failure could be interpreted as validation of the withdrawal decision or could be interpreted as a result of the withdrawal.

We also found that the reputational consequences of withdrawal diminished if the withdrawing VC firm was suffering liquidity issues, evidenced by a high percentage of invested capital or a very old most-recent fund. External audiences may attribute such withdrawals to the unfortunate circumstances in which the VC firm might find itself rather than to its underlying character (Thibaut \& Riecken, 1955; Weiner, 1985).

\section{DISCUSSION}

In the present study, we explore the relational and reputational impact to firms that are exiting business ties. In doing so, we unpack a commonly held assumption that all business ties between firms cast a positive halo on their future interactions. We examine these dynamics in the VC setting, focusing on how a VC firms' decisions to withdraw from syndicates affect their likelihood of subsequent syndication with a particular alter.

We examine the consequences of withdrawals at three levels. We first proposed that tie terminations have relational consequences, which disrupt the relationships with the abandoned collaborators and reduce the likelihood of future relationships. Consistent with that view, we demonstrate that VC firms are less likely to form ties with alters who have previously abandoned 
them or their other syndication partners. Going beyond the impact on existing relationships, we also assess the reputational costs to firms based on withdrawing from ties. We examine the flow of reputational information at both the local and global levels. We predicted that withdrawals can have global reputational consequences for the withdrawing actor by undermining its reputation for reliability. To support this argument, we demonstrate that the overall proportion of withdrawals in a VC firm's track record reduces the likelihood that any VC firm will select it as a syndication partner. Finally, although the act of terminating ties is observable globally, we argued that there can also be local reputational consequences, driven by negative private information that abandoned coinvestors spread to their immediate network contacts. In evidence, we find that a focal firm's connections to VCs that a prospective alter has previously abandoned can hinder syndication between the firm and the alter.

We also examine the interaction between the global and local consequences of withdrawal. We anticipated that negative private information originating from abandoned coinvestors of the prospective alter will draw a focal firm's attention to, and increase the credibility of, negative information in the alter's public record. As a result, we hypothesized that the presence of connections to abandoned coinvestors will increase the negative effect of the alter's overall history of withdrawals on syndication likelihood. We found exactly the opposite result: connections to abandoned coinvestors of the alters and high overall withdrawal rate of the alter attenuated each other's negative effects on the odds of syndication. This finding supports a perspective rooted in the idea that redundant information has diminishing marginal effects on behavior (Schwab, 2007). To the extent that the public information is consistent with, and thus does not modify, the priors established by the presence of private information, it has little effect on behavior. Such redundancy effect has been demonstrated in several settings, from CEOs' 
M\&A decisions (Haunschild \& Beckman, 1998) and alliance partner selection (Ozmel, Reuer, \& Gulati, 2013) to consumer reactions to product recalls (Rhee \& Haunschild, 2006). Furthermore, the findings may be driven in part by the unique features of the due diligence process, in which actors are focused on finding disqualifying information about the prospective partner. If a sufficient threshold of negative information is reached, they are likely to terminate the search for additional information.

While a VC firm's connections to abandoned syndication partners of the alter attenuate its sensitivity to the alter's past history of withdrawals, connections to non-abandoned syndication partners of the alter magnify its sensitivity to the alter's history of withdrawals. In fact, if the focal firm has no ties to non-abandoned syndication partners of the alter, the alter's withdrawal rate has virtually no effect on the probability of syndication. Our explanation for this counterintuitive finding draws on Wang's (2010) idea that referrals can attract attention to a prospective alter, but have little effect on the detailed evaluation process. Similarly, positive private information received from non-abandoned syndication partners of the alter can trigger the focal firm to begin due diligence on that alter. If that investigation reveals an extended history of withdrawals, however, the syndication is less likely to happen.

The present study contributes to the research on network evolution by demonstrating the effect of tie dissolutions on subsequent tie formation within the network. Network scholars have long been aware that the prior patterns of tie formation have a strong influence on future tie formation. Several studies have shown that actors are likely to form new collaborative ties with their past collaboration partners and those connected to their past collaboration partners (Baum, Shipilov, \& Rowley, 2003; Chung, Singh, \& Lee, 2000; Gulati, 1995b). We extend these ideas by showing that the shadow of past ties is not always positive and that withdrawal events like 
those we examine here can disrupt relationships with the abandoned coinvestors and reduce the likelihood of future syndication with their network contacts. As such, withdrawals can break the inertial preference for repeat and structurally proximate ties and thus play an important role in the network churn observed by prior research (Rowley, Greve, Rao, Baum, \& Shipilov, 2005; Sytch \& Tatarynowicz, 2014a).

Our evidence on the local reputational consequences of withdrawals also contributes to the conversation on how embeddedness in a network of relationships helps develop enforceable trust (Portes \& Sensenbrenner, 1993) by creating disincentives to engage in counter-normative behavior. The prototypical explanation is that structurally embedded actors are unwilling to betray each other for fear that news of their misbehavior might spread to shared partners and thus damage multiple productive relationships (cf. Coleman, 1988). Such a mechanism is frequently invoked to account for the propensity to transact with structurally proximate others (e.g., Gulati, 1995b), the relative scarcity of contractual safeguards in those exchanges (Robinson \& Stuart, 2007), and their greater resilience in the face of mismatched incentives (Polidoro et al., 2011). Despite the ubiquity of references to this mechanism, little research directly demonstrates that networks matter for the ex post punishment of norm violators (but see Piskorski \& Gorbatai, 2013 for an important exception). The present research is unusual in providing empirical support for this fundamental assumption, demonstrating that reputational information dissipates as it travels further across social ties and that trust is indeed more enforceable between more structurally proximate others.

Finally, the present study highlights the role of social structures in moderating the global reputational consequences of withdrawals. Prior research on reputation has largely assumed a direct link between reputation-relevant actions and reputation-related outcomes. For example, a 
reputation built on victories in certification contests increases a firm's odds of survival (Rao, 1994); unethical actions that sully an organization’s reputation reduce its attractiveness to partners (Sullivan et al., 2007); and a track record of prior success increases the likelihood of successful fundraising (Hillmann \& Aven, 2011). Global reputation is an attribute of the actor; in fact, much of the management research on reputation has treated it as an intangible property of the firm, almost inseparable from its name (Fombrun, 1996; Fombrun \& Shanley, 1990). Only recently have scholars started to recognize that reputation varies across different audiences (e.g., D'Aveni, 1996; Jensen, Kim, \& Kim, 2012; Kim \& Jensen, 2014; Lamin \& Zaheer, 2012). Our results contribute to the growing interest in the heterogeneity of reputational effects by suggesting that social ties play a powerful role in shaping how different actors react to the same alter's track record of behavior. Direct exposure to those likely to pass negative information about an alter desensitizes a focal firm to the alter's history of withdrawals; in contrast, direct ties to those most expected to pass positive information about the alter increase the attention that the focal firms pay to the alter's past behaviors. We hope the present study encourages a shift in future research from studying general reputation to a more nuanced investigation of the antecedents and consequences of reputation with individual exchange partners - in effect developing a dyadic theory of reputation.

Limitations and future research. Future studies can address several limitations of the present research that were largely unavoidable given the nature of our data. Our first challenge was that the decision to withdraw is non-randomly assigned and could be driven by unobservable factors that affect future syndication. We have addressed some obvious sources of endogeneity within the constraints of our data. Our controls for the capital availability of the firm (percentage of capital invested, age of most recent fund) address the most obvious source of time-variant 
heterogeneity; that is, capital constraint can simultaneously force premature withdrawals and make the VC firm a less attractive exchange partner. Our robustness tests using firm-fixed effects are intended to address any time-invariant unobserved heterogeneity, for example, some elements of a firm's investment strategy that simultaneously make it more likely to withdraw and also less likely to choose to engage in syndicates. Our data does not allow us to rule out other sources of endogeneity. For example, a firm may be more willing to withdraw from a syndicate if it no longer values the relationships with its syndication partners and does not plan future syndication with them. Such a scenario is especially likely if during syndication the firm had a relationship breakdown with its coinvestors or became disillusioned regarding their capabilities. In this alternative account, the withdrawing firm may, in fact, be the one avoiding the former coinvestors with whom they did not work well. ${ }^{16}$ We see the promise of future qualitative research taking a deep look at the dynamics of the relationship between syndicating VCs both before and after the withdrawal. Such research could examine the role of factors such as how future expectations of the collaboration ("the shadow of the future" as per Heide \& Miner, 1992; Poppo, Zhou, \& Ryu, 2008) play into the decision.

Another challenge we hope future research will examine is digging deeper into understanding the heterogeneity of withdrawal types and their implications. Our archival data does not allow us to look into the circumstances of each withdrawal and how these shape the attributions and interpretations that observers draw from the withdrawing firm's behavior. Some of our post hoc findings illustrate the promise of such an approach. For example, we find that

\footnotetext{
${ }^{16}$ This alternative explanation is especially important for interpreting the relational consequences of withdrawals but is less relevant to the relational consequences of withdrawals. It is not clear why a withdrawing firm might avoid not only the coinvestors that it no longer likes or respects, but every VC connected to them—or even every VC in general.
} 
withdrawals by financially constrained firms prompt less severe reputational consequences than withdrawals by firms that do not suffer such constraints. These results are consistent with an attribution process in which observers discount the informational value of an action if it is considered unavoidable rather than a deliberate choice (Weiner, 1985). However, the data did not support other predictions of attribution-based models; for example, a subsequent failure of the abandoned syndicate would serve as an ex post justification for withdrawal and also reduce reputational consequences. Such conflicting results make it important to develop a deeper understanding of the heterogeneity of withdrawals, going beyond archival data and including more qualitative or survey evidence.

Future research can also examine the generalizability of our theory to other settings. Although our analyses are set in the VC industry, we believe that the underlying mechanisms behind this dynamic are likely to generalize across a broad spectrum of interorganizational collaborations such as strategic alliances and investment banking syndication. In all of these settings, the reliability of partner contributions is considered important (Li \& Rowley, 2002; Ring \& Van de Ven, 1994), and reputational considerations play an important role in selecting partners (e.g., Sullivan et al., 2007).

Different settings, however, can exhibit variations in the local institutional context regarding the partners’ expectations (e.g., Vasudeva, Spencer, \& Teegen, 2013), the reasons behind the tie dissolutions, as well as the interpretations that audiences attach to tie dissolutions. For example, in the North American VC industry, withdrawals are easily attributable to a decision by the withdrawing firm due to investor protections enshrined in syndication contracts. In other settings, investor protections may be weaker and organizations can be ousted from collaborations by more powerful or politically connected partners. Audiences are likely to draw 
different inferences if an actor chose to withdraw from a collaboration than if it was forcibly removed.

Another limitation to the generalizability of our results comes from unique features of the VC industry, which may strengthen the importance of private information exchange for future tie formation. Venture capital firms are small and cohesive (rarely exceeding a dozen principals) and can be conceptualized easily as unitary actors that form positive or negative impressions by interacting with other VC firms. They can thus pass on such private information to other actors. In contrast, large organizations (e.g., IT or pharmaceutical companies) have multiple, highly autonomous divisions that would not necessarily share much information with each other regarding all their collaborations. ${ }^{17}$ If one division is disappointed in its dealings with a particular partner, other divisions may not necessarily pass on this experience to their partners. Thus, internal cohesion within an organizational actor can play a key role in its effectiveness as a conduit of reputational information (cf. Ghosh \& Rosenkopf, 2015; Sorenson \& Rogan, 2014; Vissa \& Chacar, 2009).

In summary, this research is an early step in building our understanding of how relationship disruptions, in this case, withdrawal from VC syndicates, can have not only dyadic implications, but also broader reputational consequences that affect relationships with third parties, both proximate and distant. We hope that future research will build on the present work

\footnotetext{
17 This is a key reason that a centralized alliance management function is important for the performance of strategic alliances - it can act as an aggregator of the alliance experience of the various units that would rarely communicate directly with one another (Kale, Dyer, \& Singh, 2002).
} 
and develop a better understanding of the underlying mechanisms, boundary conditions, and generalizability of our findings. 


\section{REFERENCES}

Ahuja, G. 2000. The duality of collaboration: Inducements and opportunities in the formation of interfirm linkages. Strategic Management Journal, 21(3): 317-343.

Ahuja, G., Polidoro, F., \& Mitchell, W. 2009. Structural homophily or social asymmetry? The formation of alliances by poorly embedded firms. Strategic Management Journal, 30(9): 941-958.

Arino, A., \& de la Torre, J. 1998. Learning from failure: Towards an evolutionary model of collaborative ventures. Organization Science, 9(3): 306-325.

Azoulay, P., Repenning, N. P., \& Zuckerman, E. W. 2010. Nasty, brutish, and short: Embeddedness failure in the pharmaceutical industry. Administrative Science Quarterly, 55(3): 472-507.

Baum, J. A. C., Shipilov, A. V., \& Rowley, T. J. 2003. Where do small worlds come from? Industrial and Corporate Change, 12(4): 697-725.

Cameron, A. C., Gelsbach, J. D., \& Miller, D. L. 2011. Robust inference with multi-way clustering. Journal of Business and Economic Statistics, 29(2): 238-249.

Chung, C. C., \& Beamish, P. W. 2010. The trap of continual ownership change in international equity joint ventures. Organization Science, 21(5): 995-1015.

Chung, S., Singh, H., \& Lee, K. 2000. Complementarity, status similarity and social capital as drivers of alliance formation. Strategic Management Journal, 21(1): 1-22.

Coleman, J. S. 1988. Social capital in the creation of human capital. American Journal of Sociology, 94: S95-S120.

D'Aveni, R. A. 1996. A multiple-constituency, status-based approach to interorganizational mobility of faculty and input-output competition among top business schools. Organization Science, 7(2): 166-189.

Dollinger, M. J., Golden, P. A., \& Saxton, T. 1997. The effect of reputation on the decision to joint venture. Strategic Management Journal, 18(2): 127-140.

Doz, Y. L. 1996. The evolution of cooperation in strategic alliances: Initial conditions or learning processes? Strategic Management Journal, 17: 55-83.

Dyer, J. H., \& Singh, H. 1998. The relational view: Cooperative strategy and sources of interorganizational competitive advantage. Academy of Management Review, 23(4): 660-679.

Faems, D., Janssens, M., Madhok, A., \& Van Looy, B. 2008. Toward an integrative perspective on alliance governance: Connecting contract design, trust dynamics and contract application. Academy of Management Journal, 51(6): 1053-1078.

Fombrun, C. 1996. Reputation: Realizing value from the corporate image. Boston: Harvard Business School Press.

Fombrun, C., \& Shanley, M. 1990. What's in a name: Reputation building and corporate strategy. Academy of Management Journal, 33(2): 233-258.

Ghosh, A., \& Rosenkopf, L. 2015. Shrouded in Structure: Challenges and Opportunities for a FrictionBased View of Network Research. Organization Science, 26(2): 622-631.

Gompers, P. 1995. Optimal investment, monitoring, and the staging of venture capital. Journal of Finance, 50: 1461-1489.

Gompers, P., Kovner, A., \& Lerner, J. 2009. Specialization and success: Evidence from venture capital. Journal of Economics \& Management Strategy, 18(3): 817-844.

Gompers, P., \& Lerner, J. 2000. Money chasing deals? The impact of fund inflows on private equity valuations. Journal of Financial Economics, 55(2): 281-325.

Gompers, P., \& Lerner, J. 2001. The money of invention: How venture capital creates new wealth. Boston, MA: Harvard Business School Press.

Gompers, P., Mukharlyamov, V., \& Xuan, Y. forthcoming. The cost of friendship. Journal of Financial Economics.

Gompers, P. A., \& Lerner, J. 1999. The venture capital cycle. Cambridge MA: MIT Press. 
Gorman, M., \& Sahlman, W. A. 1989. What do venture capitalists do? Journal of Business Venturing, 4(4): 231-248.

Greve, H. R., Baum, J. A. C., Mitsuhashi, H., \& Rowley, T. J. 2010. Built to last but falling apart: Cohesion, friction and withdrawal from interfirm alliances. Academy of Management Journal, 53(2): 302-322.

Greve, H. R., Mitsuhashi, H., \& Baum, J. A. C. 2013. Greener Pastures: Outside Options and Strategic Alliance Withdrawal. Organization Science, 24(1): 79-98.

Gulati, R. 1995a. Does familiarity breed trust? The implications of repeated ties for contractual choice in alliances. Academy of Management Journal, 38(1): 85-112.

Gulati, R. 1995b. Social structure and alliance formation patterns: A longitudinal analysis. Administrative Science Quarterly, 40(4): 619-652.

Gulati, R. 2007. Managing Network Resources: Alliances, Affiliations And Other Relational Assets. Oxford: Oxford University Press.

Gulati, R., \& Gargiulo, M. 1999. Where do interorganizational networks come from? American Journal of Sociology, 104(5): 1439-1493.

Gulati, R., \& Sytch, M. 2008. Does familiarity breed trust? Revisiting the antecedents of trust. Managerial and Decision Economics, 29: 165-195.

Gulati, R., Sytch, M., \& Mehrotra, P. 2008. Breaking up is never easy: Planning for exit in a strategic alliance. California Management Review, 50(4): 147-163.

Guler, I. 2007. Throwing good money after bad? Political and institutional influences on sequential decision making in the venture capital industry. Administrative Science Quarterly, 52(2): 248285.

Hallen, B. L., Katila, R., \& Rosenberger, J. D. forthcoming. Unpacking social defenses: A resourcedependence lens on technology ventures, venture capital, and corporate relationships. Academy of Management Journal.

Haunschild, P. R., \& Beckman, C. M. 1998. When do interlocks matter?: Alternate sources of information and interlock influence. Administrative Science Quarterly, 43(4): 815-844.

Heide, J. B., \& Miner, A. S. 1992. The shadow of the future: Effects of anticipated interaction and frequency of contact on buyer-seller cooperation. Academy of Management Journal, 35(2): 265291.

Hillmann, H., \& Aven, B. L. 2011. Fragmented networks and entrepreneurship in late imperial Russia. American Journal of Sociology, 117(2): 484-538.

Hochberg, Y. V., Lindsay, L. A., \& Westerfield, M. M. forthcoming. Resource accumulation through economic ties: Evidence from venture capital. Journal of Financial Economics.

Hochberg, Y. V., Ljungqvist, A., \& Lu, Y. 2007. Whom you know matters: Venture capital networks and investment performance. Journal of Finance, 62(1): 251-301.

Hochberg, Y. V., Ljungqvist, A., \& Lu, Y. 2010. Networking as a barrier to entry and the competitive supply of venture capital. Journal of Finance, 65(3): 829-859.

Jaccard, P. 1901. Étude comparative de la distribution florale dans une portion des Alpes et des Jura. Bulletin de la Société Vaudoise des Sciences Naturelles, 37: 547-579.

Jensen, M. 2003. The role of network resources in market entry: Commercial banks' entry investment banking, 1991-1997. Administrative Science Quarterly, 48(3): 466-497.

Jensen, M., Kim, H., \& Kim, B. K. 2012. Meeting expectations: A role-theoretic perspective on reputation. In M. L. Barnett, \& T. G. Pollock (Eds.), The Oxford handbook of corporate reputation. Oxford: Oxford University Press.

Kale, P., Dyer, J. H., \& Singh, H. 2002. Alliance capability, stock market response, and long-term alliance success: The role of the alliance function. Strategic Management Journal, 23(8): 747767.

Kale, P., \& Singh, H. 2009. Managing strategic alliances: What do we know now, and where do we go from here? Academy of Management Perspectives, 23(3): 45-62. 
Kaplan, S. N., \& Schoar, A. 2005. Private equity performance: Returns, persistence, and capital flows. Journal of Finance, 60(4): 1791-1823.

Katila, R., Rosenberger, J. D., \& Eisenhardt, K. M. 2008. Swimming with sharks: Technology ventures, defense mechanisms and corporate relationships. Administrative Science Quarterly, 53(2): 295332.

Kim, H., \& Jensen, M. 2014. Audience heterogeneity and the effectiveness of market signals: How to overcome the liability of foreignness in film exports? Academy of Management Journal, 57(5): 1360-1384.

King, G., \& Zeng, L. 1999a. Estimating absolute, relative, and attributable risks in case-control studies. Working Paper, Harvard University, Cambridge MA.

King, G., \& Zeng, L. 1999b. Logistic regression in rare events data. Political Analysis, 9: 1-27.

King, G., \& Zeng, L. C. 2001. Explaining rare events in international relations. International Organization, 55(3): 693-715.

Kleinbaum, A. M., Stuart, T., \& Tushman, M. L. 2013. Discretion within the constraints of opportunity: Gender homophily and structure in a formal organization. Organization Science, 24(5): 13161336.

Kutner, M. H., Nachtsheim, C. J., \& Neter, J. 2004. Applied Regression Models (4th Edition ed.): McGraw Hill/Irwin.

Labianca, G., \& Brass, D. J. 2006. Exploring the social ledger: Negative relationships and negative asymmetry in social networks in organizations. Academy of Management Review, 31(3): 596614.

Labianca, G., Brass, D. J., \& Gray, B. 1998. Social networks and perceptions of intergroup conflict: The role of negative relationships and third parties. Academy of Management Journal, 41(1): 55-67.

Lamin, A., \& Zaheer, S. 2012. Wall Street vs. Main Street: Firm strategies for defending legitimacy and their impact on different stakeholders. Organization Science, 23(1): 47-66.

Lawler, E. J. 2001. An affect theory of social exchange. American Journal of Sociology, 107(2): 321352.

Lawler, E. J., Thye, S. R., \& Yoon, J. 2000. Emotion and group cohesion in productive exchange. American Journal of Sociology, 106(3): 616-657.

Lawler, E. J., \& Yoon, J. 1998. Network structure and emotion in exchange relations. American Sociological Review, 63(6): 871-894.

Lee, P. M., Pollock, T. G., \& Jin, K. 2011. The contingent value of venture capitalist reputation. Strategic Organization, 9(1): 33-69.

Lerner, J. 1994. The syndication of venture capital investments. Financial Management, 23(3): 16-27.

Li, S. X., \& Rowley, T. J. 2002. Inertia and evaluation mechanisms in interorganizational partner selection: Syndicate formation among US investment banks. Academy of Management Journal, 45(6): 1104-1119.

Lincoln, J. R. 1984. Analyzing relations in dyads: Problems, models, and an application to interorganizational research. Sociological Methods \& Research, 13(1): 45-76.

Lindsey, L. 2008. Blurring firm boundaries: The role of venture capital in strategic alliances. Journal of Finance, 63(3): 1137-1168.

Nisbett, R. E., \& Ross, L. 1980. Human inference: Strategies and shortcomings of social judgment. Englewood Cliffs, NJ: Prentice-Hall.

Ocasio, W. 1997. Towards an attention-based view of the firm. Strategic Management Journal, 18: 187206.

Ozmel, U., Reuer, J. J., \& Gulati, R. 2013. Signals across multiple networks: How venture capital and alliance networks affect interorganizational collaboration. Academy of Management Journal, 56(3): 852-866.

Piezunka, H., \& Dahlander, L. 2015. Distant search, narrow attention: How crowding alters organizations' filtering of suggestions in crowdsourcing. Academy of Management Journal, 58(3): 856-880. 
Piskorski, M., \& Anand, B. 2011. Deference from low-status firms: Maintaining status without resources. Working Paper, Harvard Business School, Boston MA.

Piskorski, M. J., \& Gorbatai, A. D. 2013. Testing Coleman's social-norm enforcement mechanism: Evidence from Wikipedia. Working Paper 11-055, Harvard Business School, Boston MA.

Podolny, J. M. 1994. Market uncertainty and the social character of economic exchange. Administrative Science Quarterly, 39(3): 458-483.

Podolny, J. M. 2001. Networks as the pipes and prisms of the market. American Journal of Sociology, 107(1): 33-60.

Polidoro, F., Ahuja, G., \& Mitchell, W. 2011. When the social structure overshadows competitive incentives: The effects of network embeddedness on joint venture dissolution. Academy of Management Journal, 54(1): 203-223.

Poppo, L., Zhou, K. Z., \& Ryu, S. M. 2008. Alternative origins to interorganizational trust: An interdependence perspective on the shadow of the past and the shadow of the future. Organization Science, 19(1): 39-55.

Portes, A., \& Sensenbrenner, J. 1993. Embeddedness and immigration: Notes on the social determinants of economic action. American Journal of Sociology, 98(6): 1320-1350.

Rao, H. 1994. The social construction of reputation: Certification contests, legitimation, and the survival of organizations in the American automobile industry: 1895-1912. Strategic Management Journal, 15: 29-44.

Raub, W., \& Weesie, J. 1990. Reputation and efficiency in social interactions: An example of network effects. American Journal of Sociology, 96(3): 626-654.

Rhee, M., \& Haunschild, P. R. 2006. The liability of good reputation: A study of product recalls in the US automobile industry. Organization Science, 17(1): 101-117.

Rider, C. I. 2009. Constraints on the control benefits of brokerage: A study of placement agents in US venture capital fundraising. Administrative Science Quarterly, 54(4): 575-601.

Rider, C. I. 2012. How employees' prior affiliations constrain organizational network change: A study of U.S. venture capital and private equity. Administrative Science Quarterly, 57(3): 453-483.

Ring, P. S., \& Van de Ven, A. H. 1994. Developmental processes of cooperative interorganizational relationships. Academy of Management Review, 19(1): 90-118.

Robinson, D. T., \& Stuart, T. E. 2007. Network effects in the governance of strategic alliances. Journal of Law Economics \& Organization, 23(1): 242-273.

Rowley, T. J., Greve, H. R., Rao, H., Baum, J. A. C., \& Shipilov, A. V. 2005. Time to break up: Social and instrumental antecedents of firm exits from exchange cliques. Academy of Management Journal, 48(3): 499-520.

Schwab, A. 2007. Incremental organizational learning from multilevel information sources: Evidence for cross-level interactions. Organization Science, 18(2): 233-251.

Schwab, A., \& Miner, A. S. 2008. Learning in hybrid-project systems: The effects of project performance on repeated collaboration. Academy of Management Journal, 51(6): 1117-1149.

Seabright, M. A., Levinthal, D. A., \& Fichman, M. 1992. Role of individual attachments in the dissolution of interorganizational relationships. Academy of Management Journal, 35(1): 122160.

Shane, S., \& Cable, D. 2002. Network ties, reputation, and the financing of new ventures. Management Science, 48(3): 364-381.

Shipilov, A. V., \& Li, S. X. 2012. The missing link: The effect of customers on the formation of relationships among producers in multiplex triads. Organization Science, 23(2): 472-491.

Sorenson, O., \& Rogan, M. 2014. (When) Do Organizations Have Social Capital? In K. S. Cook, \& D. S. Massey (Eds.), Annual Review of Sociology, Vol 40, Vol. 40: 261-280. Palo Alto: Annual Reviews.

Sorenson, O., \& Stuart, T. E. 2001. Syndication networks and the spatial distribution of venture capital investments. American Journal of Sociology, 106(6): 1546-1588. 
Sorenson, O., \& Stuart, T. E. 2008. Bringing the context back in: Settings and the search for syndicate partners in venture capital investment networks. Administrative Science Quarterly, 53(2): 266294.

Srivastava, S. B. 2013. Social capital activation during the uncertainty of organizational restructuring, University of California Berkeley Working Paper.

Stern, I., Dukerich, J. M., \& Zajac, E. 2014. Unmixed signals: How reputation and status affect alliance formation. Strategic Management Journal, 35(4): 512-531.

Stuart, T. E. 1998. Network positions and propensities to collaborate: An investigation of strategic alliance formation in a high-technology industry. Administrative Science Quarterly, 43(3): 668698.

Stuart, T. E., Hoang, H., \& Hybels, R. C. 1999. Interorganizational endorsements and the performance of entrepreneurial ventures. Administrative Science Quarterly, 44(2): 315-349.

Sullivan, B. N., Haunschild, P., \& Page, K. 2007. Organizations non gratae? The impact of unethical corporate acts on interorganizational networks. Organization Science, 18(1): 55-70.

Sytch, M., \& Tatarynowicz, A. 2014a. Exploring the locus of invention: The structure and dynamics of network communities and a firm's invention performance. Academy of Management Journal, 57(1): 249-279.

Sytch, M., \& Tatarynowicz, A. 2014b. Friends and foes: The dynamics of dual social structures. Academy of Management Journal.

Thibaut, J. W., \& Riecken, H. W. 1955. Some determinants and consequences of the perception of social causality. Journal of Personality, 24: 113-133.

Townsend, R. forthcoming. Propagation of financial shocks: The case of venture capital. Management Science.

Trapido, D. 2007. Competitive embeddedness and the emergence of interfirm cooperation. Social Forces, 86(1): 165-191.

Uzzi, B. 1997. Social structure and competition in interfirm networks: The paradox of embeddedness. Administrative Science Quarterly, 42(1): 35-67.

Vasudeva, G., Spencer, J. W., \& Teegen, H. J. 2013. Bringing the institutional context back in: A crossnational comparison of alliance partner selection and knowledge acquisition. Organization Science, 24(2): 319-338.

Vissa, B., \& Chacar, A. S. 2009. Leveraging ties: The contingent value of entrepreneurial teams; external advice networks on Indian software venture performance. Strategic Management Journal, 30(11): 1179-1191.

Wang, Y. 2010. Evaluation or attention: How do social ties matter in venture financing? Unpublished doctoral dissertation chapter, MIT Sloan School of Business, Cambridge MA.

Weigelt, K., \& Camerer, C. 1988. Reputation and corporate strategy: A review of recent theory and applications. Strategic Management Journal, 9(5): 443-454.

Weiner, B. 1985. An attributional theory of achievement motivation and emotion. Psychological Review, 92: 548-573.

Wilson, R. 1968. The theory of syndicates. Econometrica, 36: 119-132.

Zhelyazkov, P. I., \& Gulati, R. 2013. Crime and punishment: The reputational consequences of withdrawal from venture capital syndicates. In L. A. Toombs (Ed.), Proceedings of the Eighteenth Annual Meeting of the Academy of Management (CD). 
Figure 1: Schematic representation of our theoretical framework

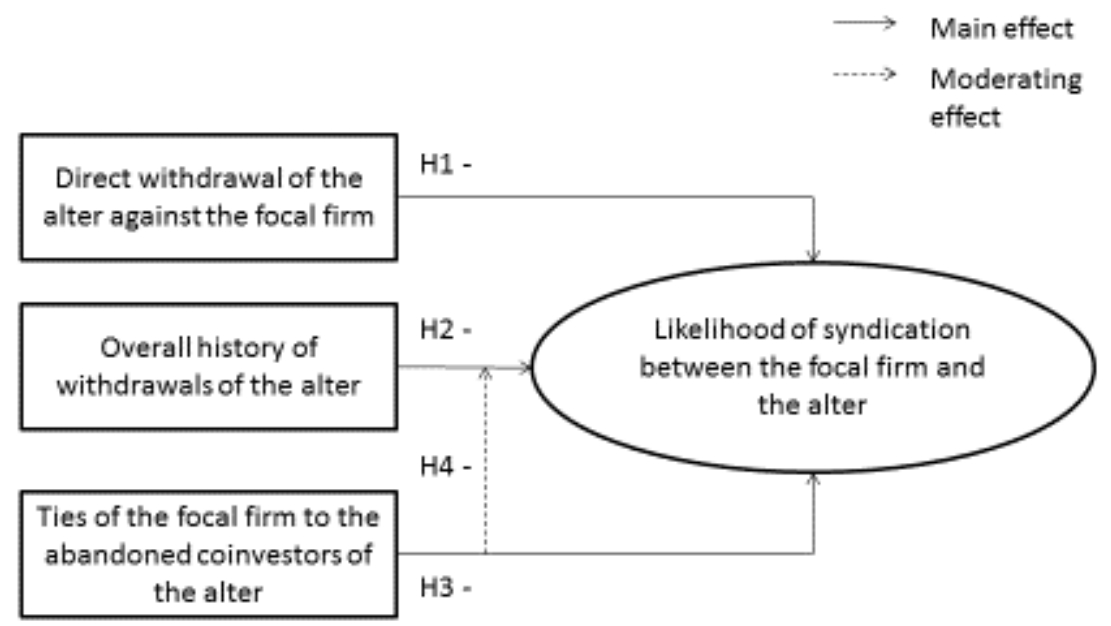

Figure 2: Predicted probability of syndication over different values of the social overlap with abandoned and non-abandoned partners of the alter

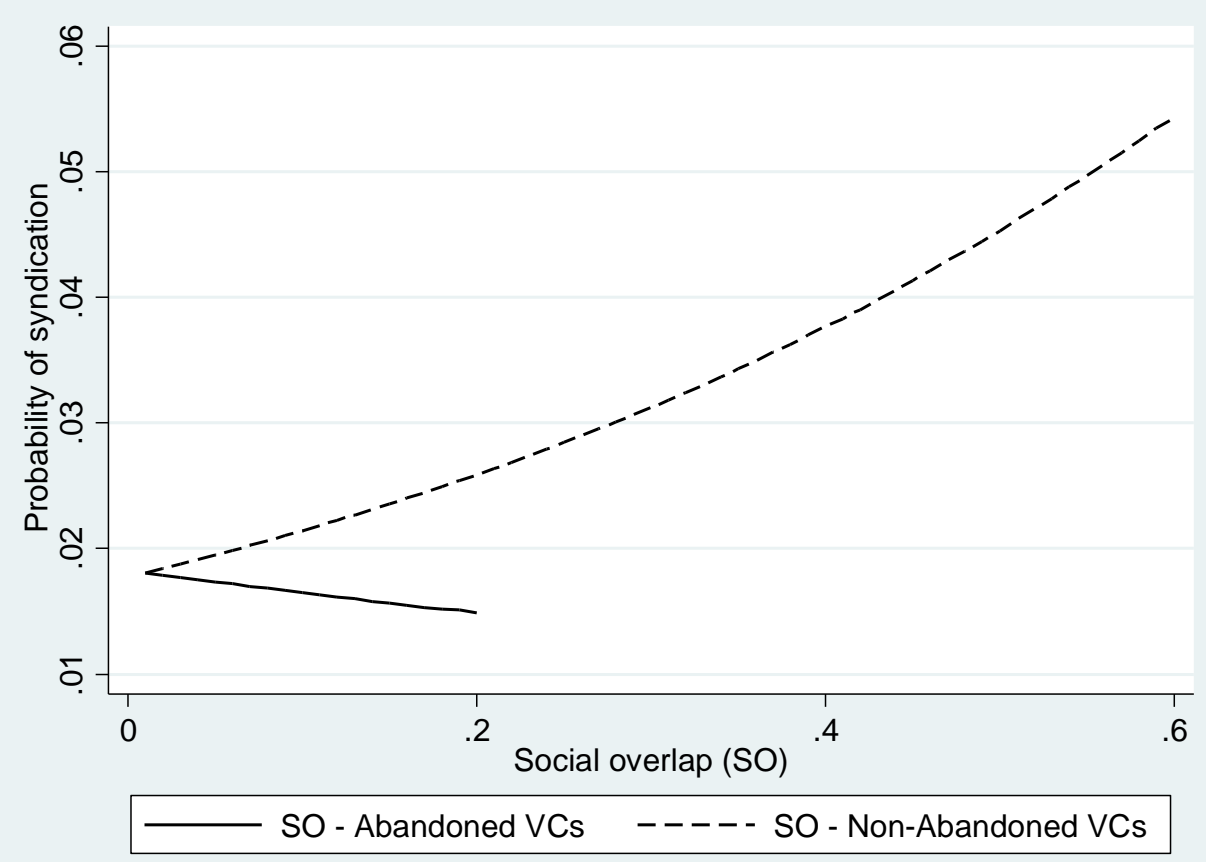

Note: All other variables held at mean values (based on Model 4, Table 2). 
Figure 3: Predicted probability of syndication over different values of focal VC firm's overall withdrawal rate.

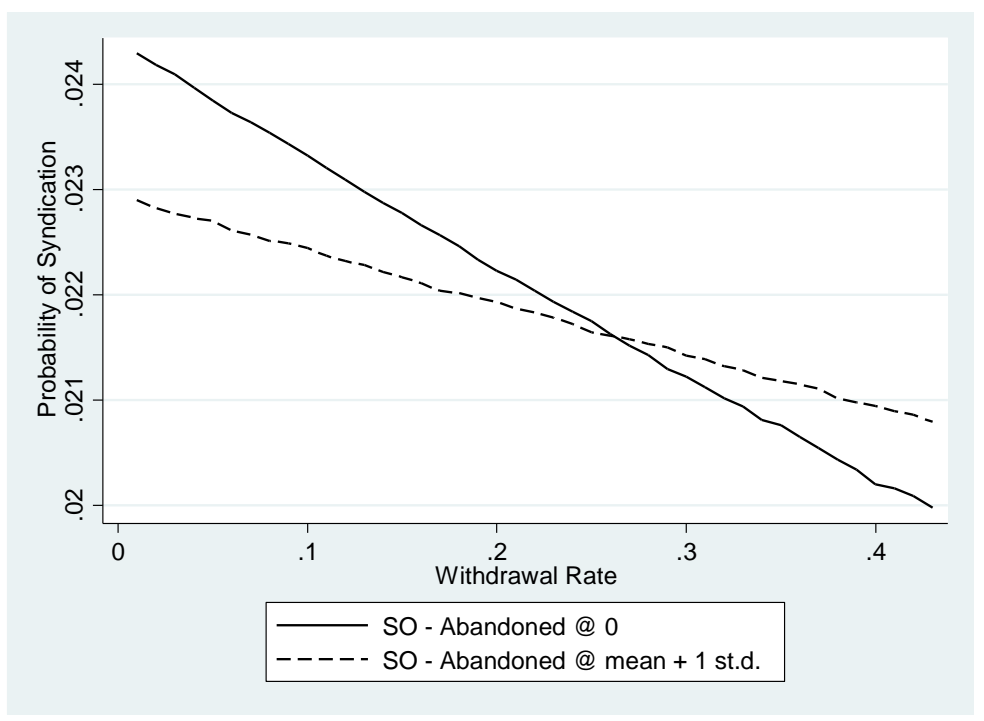

Note: Sets the other VC firm's social overlap with the abandoned coinvestors of the focal firm at either zero or one standard deviation above mean. All other variables held at mean values (based on Model 5, Table 2).

Figure 4: Predicted probability of syndication over different values of the focal VC firm's overall withdrawal rate.

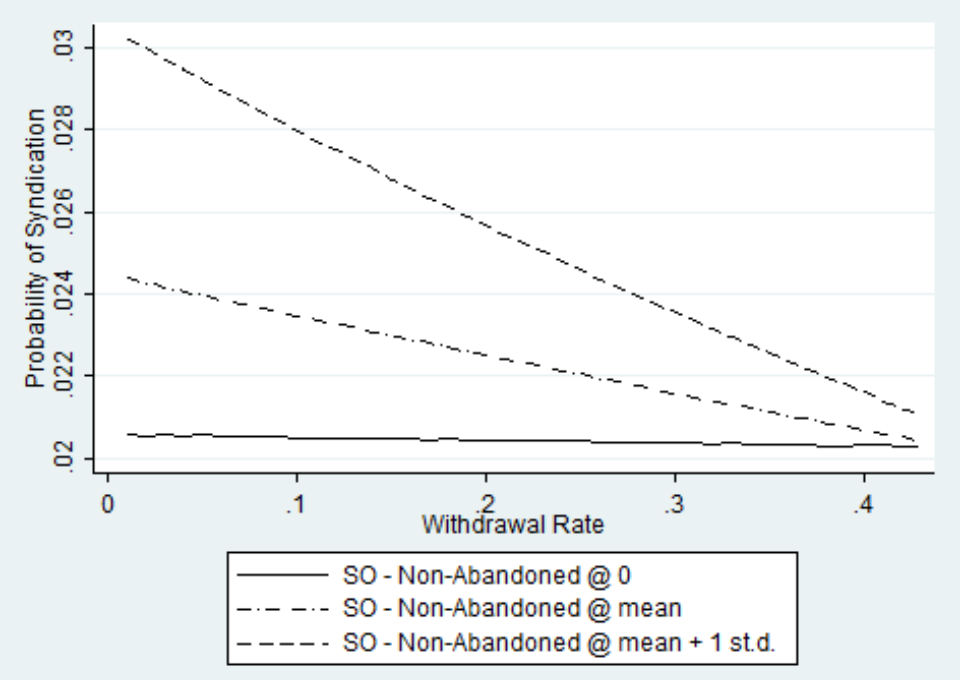

Note: Sets the other VC firm's social overlap with the non-abandoned coinvestors of the focal firm at zero, at mean, or one standard deviation above mean. All other variables held at mean values (based on Model 5, Table 2). 


\section{TABLE 1: Descriptive statistics and correlation table of the dataset ${ }^{\mathrm{a}}$}

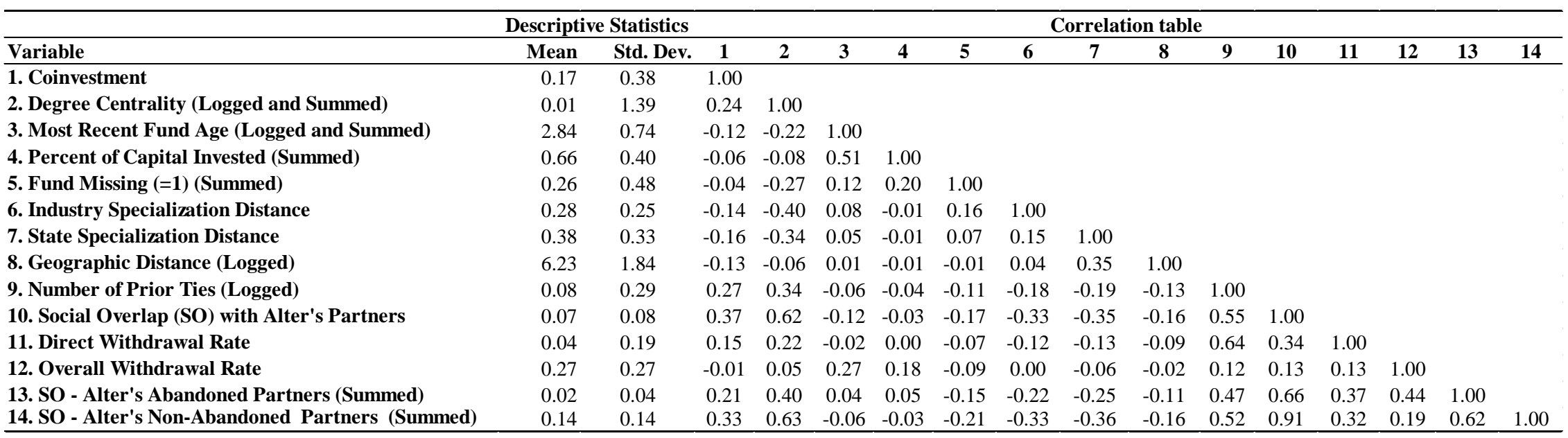

a Across 250,730 observations. 
Table 2: Rare event logit model predicting the likelihood of syndication ${ }^{b}$

\begin{tabular}{|c|c|c|c|c|c|}
\hline Independent Variables & Model 1 & Model 2 & Model 3 & Model 4 & Model 5 \\
\hline Degree Centrality (Logged and Summed) & $\begin{array}{l}0.04+ \\
(0.03)\end{array}$ & $\begin{array}{l}0.04+ \\
(0.03)\end{array}$ & $\begin{array}{l}0.05^{*} \\
(0.03)\end{array}$ & $\begin{array}{l}0.06^{*} \\
(0.03)\end{array}$ & $\begin{array}{l}0.05^{+} \\
(0.03)\end{array}$ \\
\hline Most Recent Fund Age (Logged and Summed) & $\begin{array}{c}-0.20^{* *} \\
(0.02)\end{array}$ & $\begin{array}{c}-0.19^{* *} \\
(0.02)\end{array}$ & $\begin{array}{c}-0.17^{* *} \\
(0.02)\end{array}$ & $\begin{array}{c}-0.18^{* *} \\
(0.02)\end{array}$ & $\begin{array}{c}-0.17^{* *} \\
(0.02)\end{array}$ \\
\hline Percent of Capital Invested (Summed) & $\begin{array}{c}-0.07 \\
(0.05)\end{array}$ & $\begin{array}{c}-0.07 \\
(0.05)\end{array}$ & $\begin{array}{c}-0.05 \\
(0.05)\end{array}$ & $\begin{array}{c}-0.04 \\
(0.05)\end{array}$ & $\begin{array}{c}-0.05 \\
(0.04)\end{array}$ \\
\hline Fund Missing (=1) (Summed) & $\begin{array}{c}0.14^{* *} \\
(0.03)\end{array}$ & $\begin{array}{l}0.14^{* *} \\
(0.03)\end{array}$ & $\begin{array}{c}0.13^{* *} \\
(0.03)\end{array}$ & $\begin{array}{c}0.15^{* *} \\
(0.03)\end{array}$ & $\begin{array}{c}0.15^{* *} \\
(0.03)\end{array}$ \\
\hline Industry Specialization Distance & $\begin{array}{c}-0.67^{* *} \\
(0.10)\end{array}$ & $\begin{array}{c}-0.67^{* *} \\
(0.10)\end{array}$ & $\begin{array}{c}-0.66^{* *} \\
(0.10)\end{array}$ & $\begin{array}{c}-0.68^{* *} \\
(0.10)\end{array}$ & $\begin{array}{c}-0.66^{* *} \\
(0.10)\end{array}$ \\
\hline State Specialization Distance & $\begin{array}{c}-0.50 * * \\
(0.08)\end{array}$ & $\begin{array}{c}-0.50^{* *} \\
(0.08)\end{array}$ & $\begin{array}{c}-0.51^{* *} \\
(0.08)\end{array}$ & $\begin{array}{c}-0.52^{* *} \\
(0.08)\end{array}$ & $\begin{array}{c}-0.50 * * \\
(0.08)\end{array}$ \\
\hline Geographic Distance (Logged) & $\begin{array}{c}-0.09 * * \\
(.01)\end{array}$ & $\begin{array}{c}-0.09 * * \\
(.01)\end{array}$ & $\begin{array}{c}-0.09 * * \\
(.01)\end{array}$ & $\begin{array}{c}-0.09 * * \\
(.01)\end{array}$ & $\begin{array}{c}-0.09 * * \\
(.01)\end{array}$ \\
\hline Lincoln Autoregressive Term & $\begin{array}{c}3.05^{* *} \\
(0.15)\end{array}$ & $\begin{array}{c}3.04 * * \\
(0.15)\end{array}$ & $\begin{array}{c}3.02 * * \\
(0.15)\end{array}$ & $\begin{array}{c}3.10^{* *} \\
(0.15)\end{array}$ & $\begin{array}{c}3.06^{* *} \\
(0.16)\end{array}$ \\
\hline Number of Prior Ties (Logged) & $\begin{array}{l}0.55^{* *} \\
(0.06)\end{array}$ & $\begin{array}{c}0.64^{* *} \\
(0.06)\end{array}$ & $\begin{array}{c}0.65 * * \\
(0.06)\end{array}$ & $\begin{array}{c}0.69 * * \\
(0.05)\end{array}$ & $\begin{array}{l}0.72 * * \\
(0.05)\end{array}$ \\
\hline Social Overlap (SO) with Alter's Partners & $\begin{array}{c}3.32 * * \\
(0.42)\end{array}$ & $\begin{array}{l}3.29 * * \\
(0.43)\end{array}$ & $\begin{array}{l}3.34^{* *} \\
(0.42)\end{array}$ & & \\
\hline Direct Withdrawal Rate (Summed) & & $\begin{array}{c}-0.22^{* *} \\
(0.05)\end{array}$ & $\begin{array}{c}-0.18^{* *} \\
(0.04)\end{array}$ & $\begin{array}{c}-0.15^{* *} \\
(0.04)\end{array}$ & $\begin{array}{c}-0.15^{* *} \\
(0.04)\end{array}$ \\
\hline Overall Withdrawal Rate (Summed) - A & & & $\begin{array}{c}-0.50 * * \\
(.07)\end{array}$ & $\begin{array}{c}-0.40^{* *} \\
(.06)\end{array}$ & $\begin{array}{c}-0.43^{* *} \\
(.07)\end{array}$ \\
\hline SO - Alter's Abandoned Partners (Summed) & & & & $\begin{array}{c}-1.04^{* *} \\
(0.33)\end{array}$ & $\begin{array}{l}-0.64^{*} \\
(0.33)\end{array}$ \\
\hline SO - Alter's Non-Abandoned Partners (Summed) & & & & $\begin{array}{l}1.93^{* *} \\
(0.23)\end{array}$ & $\begin{array}{l}1.95 * * \\
(0.19)\end{array}$ \\
\hline A* SO - Alter's Abandoned Partners (Summed) & & & & & $\begin{array}{c}4.94 * * \\
(0.74)\end{array}$ \\
\hline A * SO - Alter's Non-Abandoned Partners (Summed) & & & & & $\begin{array}{c}-5.67^{* *} \\
(0.63)\end{array}$ \\
\hline Constant & $\begin{array}{c}-3.87^{* *} \\
(0.23)\end{array}$ & $\begin{array}{c}-3.87^{* *} \\
(0.23)\end{array}$ & $\begin{array}{c}-3.86^{* *} \\
(0.23)\end{array}$ & $\begin{array}{c}-3.87^{* *} \\
(0.21)\end{array}$ & $\begin{array}{c}-3.91^{* *} \\
(0.23)\end{array}$ \\
\hline Adj. Pseudo-R sq. (percent) & 21.52 & 21.54 & 21.57 & 21.62 & 21.77 \\
\hline
\end{tabular}

b Across 250,730 observations. Year fixed effects. Robust standard errors clustered by both firm identifiers and year in parentheses; significance levels based on two-tailed tests.

$+p<.10$

$* p<.05$

$* * p<.01$ 